Boris Fehse, Jörn Walter, Jens Reich, Lilian Marx-Stölting, Anja Pichl und Hannah Schickl

\title{
9. Genome-Editing und Einzelzellanalyse: Neue Methoden und ihre Implikationen für Forschung, Anwendung und Gesellschaft
}

In den letzten Jahren haben sich zwei Methoden rasant weiterentwickelt, die die ganze Bandbreite der Gentechnologien und damit alle von der IAG Gentechnologiebericht bearbeiteten Themen beeinflussen: Das Genome-Editing („Genomchirurgie“), das national wie international bereits seit 2015 breit diskutiert wird, und die Einzelzellanalyse, die noch kaum in der öffentlichen Wahrnehmung angekommen ist. Beide Methoden waren bereits Gegenstand eigenständiger Publikationen der IAG. Als erste deutschsprachige Analyse zum Thema veröffentlichten die Mitglieder der IAG 2015 eine Darstellung der ethischen und rechtlichen Aspekte zur Genomchirurgie in der menschlichen Keimbahn, d. h. einer gezielten vererbbaren Veränderung des menschlichen Genoms (Reich et al., 2015). Zur Einzelzellanalyse wurde 2019 (Walter/Schickl) ebenfalls die erste umfassende Stellungnahme im deutschen Sprachraum publiziert. Darin diskutierten namhafte Autor*innen den biologischen Sachstand und medizinische Anwendungshorizonte, aber auch ethische und rechtliche Aspekte sowie einige Problemfelder und Indikatoren. Aufgrund ihrer Relevanz für die Weiterentwicklung der Gentechnologien sollen beide Methoden im „Fünften Gentechnologiebericht“ erörtert werden. Im Folgenden werden daher zunächst Genome-Editing und im Anschluss die Einzelzellanalyse jeweils in ihren Grundzügen und ihrer Funktionsweise kurz vorgestellt, ihre Bedeutung für die weitere Entwicklung der Gentechnologien skizziert und die einschlägigen ethischen und rechtlichen Kontroversen um sie dargestellt. 


\subsection{Genome-Editing}

\subsubsection{Wissenschaftliche Grundlagen ${ }^{1}$}

Unter dem Begriff „Genome-Editing“ (deutsch „Genomeditierung“) werden unterschiedliche Verfahren der Gentechnik zusammengefasst, mit denen gezielt und relativ präzise Basenabfolgen in Genomen lebender Zellen verändert werden können. Bei der „klassischen“ Form des Genome-Editing kommen sogenannte DNA- bzw. Genscheren zum Einsatz. Dies sind bestimmte Enzyme (Moleküle), die DNA basengenau schneiden können. Im Reigen der verschiedenen bereits bekannten DNA-Scheren stechen vor allem die CRISPR/Cas-Enzymkomplexe heraus. Diese zeichnen sich durch ihre flexible Nutzbarkeit, ihre schnelle Anwendbarkeit, die Präzision und die geringen Kosten für die tägliche Arbeit im Labor aus. Das Akronym „CRISPR“ steht für „Clustered Regularly Interspaced Short Palindromic Repeats" und bezeichnet ursprünglich eine bestimmte Region auf der DNA von Bakterien, die auffällige DNA-Abschnitte mit kurzen palindromen Sequenzwiederholungen ${ }^{2}$ aufweisen. „Cas“ steht für „CRISPR associated Protein“, d. h. für ein Enzym, das mit diesen Sequenzen in Verbindung steht. Ein solches Protein ist Cas9. Gemeinsam bilden CRISPR und Cas9 Komplexe, die der natürlichen bakteriellen adaptiven Immunantwort dienen, $d$. h. der Fremd-Abwehr eindringender Bakteriophagen. ${ }^{3}$ Im Zuge eines Virenbefalls werden DNA-Abschnitte des viralen Genoms in das Bakteriengenom quasi als Infektionsgedächtnis integriert. Überlebt das Bakterium die Infektion, werden diese integrierten Abschnitte in eine kurze (CRISPR- bzw. cr) RNA abgelesen, ${ }^{4}$ welche dem CRISPR/Cas9-Schneidekomplex zur passgenauen Erkennung der Virus-DNA und deren nachfolgendem Zerschneiden dient.

Dieses natürliche Abwehrsystem gegen Fremd-DNA wurde nach seiner Entschlüsselung derart umprogrammiert, dass man mithilfe künstlich im Labor hergestellter RNA,

1 Siehe hierzu auch Clemens (Kap. 7).

2 Eine palindromische Sequenz bezeichnet in der Genetik einen kurzen Abschnitt einer doppelsträngigen DNA-Sequenz, der von vorne oder hinten (auf dem Komplementärstrang) gelesen gleichbleibt, da die beiden komplementären Stränge in einer Richtung gelesen die gleiche Basenabfolge besitzen. Ein Beispiel wäre die Sequenz GAATTC. Siehe unter: https://flexikon.doccheck.com/de/Palindromische_Sequenz [20.04.2021].

3 Spezielle Viren, die nur Bakterien angreifen.

4 RNA steht für Ribonukleinsäure. In der Zelle üben RNAs viele unterschiedliche Funktionen aus, u. a. als messenger-RNA bzw. Boten-RNA, welche als Bindeglied zwischen der Erbinformation auf der DNA (Desoxyribonukleinsäure) und den Proteinen fungiert. Genau wie DNA besteht RNA aus Nukleotiden, deren Basenfolge die Abfolge von Aminosäuren, den Bausteinen der Proteine, codiert. Anders als die doppelsträngige und stabile DNA ist RNA einzelsträngig und nicht sehr stabil, wird in der Zelle also relativ rasch wieder abgebaut. 
der sogenannten Guide-RNA, jede genomische DNA an der zu der RNA passenden Stelle im Genom zerschneiden kann. Des Weiteren wurde das Verfahren gentechnologisch so optimiert, dass man mit bakteriellen „Genscheren“ (fast) jede Stelle im Genom gezielt ansteuern und Veränderungen (Mutationen) erzeugen kann.

Für die gewünschte Veränderung im Genom induziert die Genschere (d. h. das CRISPR/Cas-System) zunächst einen Bruch der DNA-Sequenz (d. h. einen sogenannten DNA-Doppelstrangbruch). Erst im Ergebnis seiner ,natürlichen“ Reparatur durch zelleigene Enzyme entsteht die angestrebte genetische Veränderung. Für die Reparatur eines Doppelstrangbruchs benutzt die Zelle vorwiegend zwei verschiedene Verfahren: die sog. homologe Rekombination ${ }^{5}$ oder die nicht-homologe End-zu-End-Verknüpfung. ${ }^{6}$ Mit der Methode der homologen Rekombination kann ein neuer DNA-Abschnitt mit der gewünschten Sequenz ins Genom eingebaut werden. Das erreicht man im Experiment dadurch, dass nicht nur die Genschere (Guide-RNA + Cas9) in die Zelle eingebracht wird und einen Schnitt an der angestrebten Stelle (Zielsequenz) des Genoms setzt. Zusätzlich bringt man gleichzeitig auch eine geeignete DNA-Sequenz als Reparatur-Matrize in die Zelle ein. Diese besteht aus einem Sequenzabschnitt, dessen äußere Enden genau mit den Schnitträndern übereinstimmen (homolog sind). Dazwischen enthält die Matrize zusätzlich die neu einzuführende Teilsequenz. Bei dem „copy/paste“-Mechanismus der homologen Rekombination wird nicht nur der identische, sondern auch der neue Bereich in die geschnittene Lücke eingefügt und „vernäht“, sodass, wenn alles klappt, die ursprüngliche Gensequenz nach Reparatur auch den neuen Abschnitt enthält. Mithilfe dieses Verfahrens kann man sowohl gezielt Korrekturen von Mutationen erreichen als auch neue Genabschnitte einfügen. Dies ist aber ein komplexer Prozess, der je nach behandeltem Zelltyp vergleichsweise ineffizient ist. So funktioniert das Verfahren z. B. nur in sich teilenden Zellen und je nach Zelltyp mit unterschiedlichen Erfolgsraten. Ein weiteres Problem ist, dass sich in den Zellen auch der alternative, „einfachere“ Reparaturweg des Nicht-Homologen-End-Joining (NHEJ) durchsetzen und die Reparatur bestimmen kann. Dabei fügen zelleigene Reparaturenzyme die beiden „losen“ DNAStränge „einfach“ wieder zusammen. Hierbei kommt es zu einem Verlust (gelegentlich allerdings auch zur Einfügung) von Nukleotid-Bausteinen im Bereich der Zielsequenz. ${ }^{7}$ Es entsteht dabei auf jeden Fall eine lokale (nicht im Detail vorhersagbare) Veränderung im Gen. Dieses Verfahren setzt man ein, um Gene schnell und gezielt zu mutieren

5 Auch „Homology-directed repair“. Natürlicherweise benutzt die Zelle das Schwesterchromosom als Vorlage für einen „copy/paste“ Prozess.

6 „Non-homologous end-joining“ (NHEJ).

7 Sog. Indels (= Insertionen [= Basengewinn] oder Deletionen [= Basenverlust]) 
oder sie auszuschalten - man muss dann aber immer überprüfen, welche Mutation am Genort entstanden ist. ${ }^{8}$

\subsubsection{Entwicklung und Stand der Technologie}

Die Grundlagen der Entwicklung des heutigen Genome-Editing wurden bereits 1987 gelegt, als die ersten CRISPR-Loci im Rahmen der Grundlagenforschung in Japan am Genom von E.-coli-Bakterien entdeckt wurden (Ishino, 1987). Der spanische Mikrobiologe Francisco Mojica entdeckte später, dass sich CRISPR-Loci in unterschiedlichen Bakterien und sogar Archebakterien finden lassen und prägte den Begriff CRISPR. Bis dahin und auch in der Folge wurden diese vergleichsweise wenig interessanten bakteriellen Genabschnitte praktisch ohne größeren Förderungsmittelaufwand erforscht (Ledford, 2017). 2005 stellte Eugene Koonin die Hypothese auf, dass diese Sequenzen eine Rolle in der Immunantwort von Bakterien spielen (Makarova et al., 2006; Jinek et al., 2012; Broad Institute, 2021). 2010 folgte die Entdeckung durch Sylvain Moineau (Garneau et al., 2010), dass Cas9 durch eine crRNA gesteuert wird und DNA schneidet. 2012 gelang es schließlich Virginijus Siksnys aus Litauen nachzuweisen, dass das System über die Benutzung spezifischer crRNAs gezielt benutzt werden kann, um Schnitte in einer beliebigen Ziel-DNA zu setzen (Gasiunas, 2012). Allerdings wurde die Publikation dieser (deutlich früher eingereichten) Arbeit aus dem Siksnys-Labor durch die Journale verzögert (Lander, 2016), sodass die Publikation von Jennifer Doudna und Emmanuelle Charpentier über die „Programmierbarkeit“ von Cas9 durch synthetische RNA und deren vielfältige Anwendungsmöglichkeiten zuerst erschien (Jinek et al., 2012). Die entscheidende Entdeckung für das Genome-Editing war die Beobachtung, dass man mithilfe frei wählbarer Guide-RNA-Abschnitte, die man an immer gleichbleibende RNA-Anteile künstlich fusioniert, quasi beliebige, Zielsequenz-spezifische Schneidewerkzeuge erzeugen kann. Zudem zeigte sich, dass man dieses System künstlich in nahezu allen Zellen (auch bei Eukaryonten, also Zellen mit Zellkern, z. B. menschlichen Zellen) einbringen und nutzen kann. Seitdem erfolgte eine rasante weltweite Verbreitung der Technik und es erschienen zahllose Publikationen zu möglichen Anwendungen. In der Grundlagenforschung wird die Methode breit, in verschiedensten Organismen und Zellsystemen, eingesetzt und ersetzt komplizierte frühere Manipulationsverfahren. 2020 bekamen Emmanuelle Charpentier und Jennifer Doudna den Nobelpreis für Chemie. Das Nobelpreis-Komitee begründete dies u. a. damit, dass CRISPR/Cas die Grundlagenfor-

8 Eine detailliertere Darstellung der unterschiedlichen Mechanismen findet sich in Fehse/Abramowski-Mock, 2021. 
schung revolutioniere und neuartige Kulturpflanzen hervorgebracht habe sowie bahnbrechende medizinische Behandlungsmöglichkeiten erwarten lasse. ${ }^{9}$

Die Vorteile von CRISPR/Cas9 liegen auf der Hand: die Methode ist schnell, günstig, präzise und leicht einsetzbar. Grundsätzlich ist die Veränderung mehrerer Stellen im Genom gleichzeitig oder kurz nacheinander möglich (Multiplexing). Es können Gene fremder Arten übertragen werden, wodurch klassische transgene (artübergreifende) Änderungen möglich werden. Es ist überdies möglich, Änderungen so vorzunehmen, dass keine „Rückstände“ von Fremdgen-Anteilen im Genom verbleiben. Wenn dabei nur einzelne Mutationen eingefügt werden, sind diese dann nicht mehr oder nur schwer als gentechnisch herbeigeführt erkennbar. Dieser Aspekt spielt vor allem in der Diskussion um die Kennzeichnungspflicht von durch CRISPR/Cas modifizierten Organismen eine wichtige Rolle (siehe unten 9.1.4.1).

Bei aller Euphorie weist die Methode auch einige technische Probleme auf, an deren Lösung noch zu arbeiten ist. Dazu gehören sog. Off-Target-Effekte, das sind Schnitte oder Chromosomenveränderungen an anderer als der gewünschten Stelle im Genom. Auch sind, wie oben angedeutet, die On-Target-Effekte nicht komplett steuerbar - die eingefügten Basenveränderungen (Indels) entstehen weitgehend spontan, sind nicht kontrollierbar und haben so nicht immer den angestrebten Effekt. Statt einer erwünschten Genkorrektur über homologe Rekombination mithilfe einer künstlichen Matrize kommt es oft zu einem „einfachen“ Knockout (Genmutation) per NHEJ. Die eingesetzten bakteriellen Proteine können bei menschlichen oder tierischen Organismen unbeabsichtigte Nebenwirkungen im Immunsystem auslösen. Die Effizienz von CRISPR/Cas ist zwar sehr hoch im Vergleich zu anderen Genscheren, aber für den Einsatz am Menschen ist selbst eine geringe Fehlerrate möglicherweise noch zu hoch. Alternativen, die bereits erforscht werden, nutzen daher andere Proteine wie etwa CfP1 (ein anderes schneidendes Protein), dCas9 (disabled Cas9, das nicht mehr schneidet, sondern nur die richtige Stelle im Genom findet und ggf. andere Faktoren dorthin lotsen kann), Mini-Cas9 (das kleiner ist als Cas9 und besser in den Zellkern eindringen kann) etc.

Techniken des Genome-Editing werden ständig weiterentwickelt, um sie zuverlässiger, präziser und breiter einsetzbar zu machen. Auf Basis von dCas9 wurden so z. B. alternative Techniken des Genome-Editing entwickelt. Dazu gehört das Base-Editing, bei dem kein Doppelstrangbruch mehr erzeugt wird, sondern nur noch einzelne Basen

9 „There is enormous power in this genetic tool, which affects us all. It has not only revolutionised basic science, but also resulted in innovative crops and will lead to ground-breaking new medical treatments." (Claes Gustafsson, Chair of the Nobel Prize Committee for Chemistry; siehe unter: https://www.nobelprize.org/prizes/chemistry/2020/press-release/ [21.04.2021]). 
modifiziert und in der Folge umgewandelt (ausgetauscht) werden. Eine andere Abwandlung stellt das PRIME-Editing dar, bei dem ausgehend von der Erkennungsstelle der guide-RNA ein kurzer Bereich des Genoms durch eine neue Sequenz quasi überschrieben wird. Schließlich gibt es inzwischen auch RNA-Editoren, die nicht die (genomische) DNA als Ziel haben, sondern die abgelesene mRNA verändern - die Gene selbst bleiben dabei unverändert. Eine weitere vielversprechende neue Anwendung ist das „Epigenome-Editing“. Hier nimmt man gar keine gezielten Genveränderungen vor, sondern man verändert die epigenetischen Modifikationen wie z. B. DNA-Methylierung an Genen und damit das An- und Ausschalten von Genen. ${ }^{10}$ Beim Epigenome-Editing werden epigenetische Modifikationsenzyme durch Cas9-unterstützte Verfahren an Genorte herangeführt, um die Zugänglichkeit der DNA für die Genexpression zu beeinflussen und Gene so dauerhaft an- oder abzuschalten. Bisherige Versuche deuten an, dass so eine effiziente nachhaltige Regulation in der Tat erreicht werden kann (Nunez et al., 2021).

\subsubsection{Grenzen des Wissens und der Kommunikation}

Den sich rasant wandelnden und hoch spezialisierten Forschungsstand allgemeinverständlich darzustellen und dabei keine überzogenen Erwartungen und verzerrten Vorstellungen zu wecken, stellt sehr hohe Anforderungen an Wissenschaftskommunikation und -journalismus. Diese einzulösen, wird durch strukturelle Bedingungen gesellschaftlicher Subsysteme (Stichwort Antragslyrik in der Forschungsförderung, Aufmerksamkeitsökonomie der Medien, Biotech-Startups u. a.), in denen Erwartungen und Versprechen eine konstitutive Rolle spielen, erschwert. Darüber hinaus ist der Rückgriff auf Metaphern zur Erläuterung wissenschaftlicher Methoden, objekte und Technologien gleichermaßen notwendig wie problematisch, wie die vielfach kritisierte (vgl. u. a. O‘Keefe et al., 2015; GeN, 2019; EGE, 2021), jedoch omnipräsente Metapher des „Editierens“ des Genoms zeigt. Diese Metapher stellt die betreffenden komplexen biologischen Vorgänge in stark vereinfachender Form dar und lädt durch diesen Reduktionismus zu überzogenen Erwartungen hinsichtlich der Präzision, Sicherheit und Machbarkeit von gezielten therapeutischen und sonstigen Eingriffen ins Genom ein. Nichtsdestotrotz hält auch dieser Text bewusst an ihr fest, mangels besserer Alternativen und in Anbetracht der Notwendigkeit, sich mittels Bildern verständlich zu machen. Des Weiteren geht die Kontextbezogenheit von Sachstandsbeschreibungen und die Relativität von Begriffen in der öffentlichen Kommunikation häufig verloren. Dies betrifft bspw. die Konjunktur des Präzisionsbegriffs, der bisher wohl jeder neuen Gentechno-

10 Siehe zum ethischen Diskurs um Epigenome- und Genome-Editing Alex/Winkler, Kap. 13. 
logie im öffentlichen Raum - häufig entgegen differenzierterer Erklärungen seitens involvierter Forscher*innen - angeheftet und bei der jeweils nächsten technischen Weiterentwicklung an diese weitergereicht wurde. So wird das zuvor häufig als äußerst präzise beschriebene CRISPR/Cas9-Reparatursystem in einem Nature-Artikel zum oben eingeführten PRIME-Editing (Ledford, 2019) als ,unzuverlässig“ bezeichnet. Es ist sogar von einem ,unkontrollierbaren Gemisch von Editierungen, die zwischen den Zellen variieren“ (ebd.: 465, Übersetzung AP), die Rede. Sowohl die Metapher des „Editierens“ als auch die Konjunktur des Präzisionsbegriffs in den Debatten um Genome-Editing verdecken das Problem, dass globale Auswirkungen selbst präziser Änderungen des Genoms bisher oft nicht vorhersagbar sind, weil über die Funktionsweise und Interaktion von Genen, untereinander und mit der Umwelt, weiterhin nur sehr begrenztes Wissen besteht ${ }^{11}$ und auch technische Probleme wie z. B. On- und Off-Target-Effekte und Mosaikbildung beim Einsatz von Genome-Editing noch nicht gelöst sind.

Der weltweite Einsatz von Genome-,,Editing“ in der Forschung sowie die oben skizzierten neuen Techniken führen natürlich auch zu einer beständigen Erweiterung des Wissens über die Funktionsweise des Genoms von Menschen und anderen Lebewesen. Jedoch scheinen zum jetzigen Zeitpunkt die technischen Fertigkeiten das Wissen um deren Auswirkungen zu übersteigen. Die Spannung zwischen anscheinend exponentiell anwachsenden Fähigkeiten der gentechnologischen Veränderung und Kontrolle biologischer Abläufe und dem begrenzten Wissen über Funktion und Interaktion von Genen ist selbstverständlich nicht erst mit der Entwicklung von CRISPR/Cas aufgetreten. Jedoch könnte dessen vergleichsweise niedrigschwellige Einsetzbarkeit dank der einfachen und kostengünstigen Anwendung und hoher Erwartungen zu einem breiteren und verfrühten Einsatz führen. Selbst die strittigste und lange Zeit als rote Linie betrachtete Anwendung des Genome-Editing in der menschlichen Keimbahn ist bereits vorgenommen worden (siehe unter 9.1.4.2 und Alex/Winkler, Kap. 13).

\subsubsection{Ethische und rechtliche Kontroversen um das Genome-Editing}

Genome-Editing hat intensive ethische und rechtliche Diskussionen im Zusammenhang mit seinen vielseitigen Einsatzmöglichkeiten ausgelöst. Dazu zählen sowohl die Grundlagenforschung, als auch die Entwicklung von Arzneimitteln und Gentherapien, die Keimbahnmodifikation, die Herstellung von Biomaterialien und Mikroorganismen,

11 So heißt es in der Leopoldina-Stellungnahme zum Genome-Editing von 2015: „Wir sind weit davon entfernt, das ,Konzert der Gene des Menschen zu verstehen. Sogar eine sehr gezielte Veränderung der genetischen Information in der menschlichen Keimbahn kann unvorhersehbare Auswirkungen mit sich bringen“" (Leopoldina, 2015: 11 f.). 
die Entwicklung neuer Pflanzensorten mit möglicherweise vorteilhafteren Eigenschaften und von Gene Drives (siehe Kolleck/Sauter, Kap. 10). Auch Tiere, die gegen bestimmte Krankheiten immun oder dem Menschen genetisch ähnlicher sind und sich daher als Versuchstiere zur Modellierung menschlicher Krankheiten oder zur Herstellung von Spenderorganen (Xenotransplantation) besser eignen, lassen sich mithilfe von Genome-Editing erzeugen. Im Folgenden stellen wir die aktuellen und besonders polarisierenden ethischen und rechtlichen Kontroversen um genomeditierte Pflanzen und Keimbahnmodifikationen kurz vor.

\subsubsection{Ethische Aspekte genomeditierter Pflanzen ${ }^{12}$}

Beim Einsatz von Genome-Editing in der Pflanzenzüchtung und Landwirtschaft stehen Regulierungsfragen im Mittelpunkt der Debatte. Es ist heftig umstritten, ob mittels Genome-Editing erzeugte Pflanzen, die lediglich kleine, schwer nachweisbare Mutationen und keine Fremdgene enthalten, als GVO (gentechnisch veränderte Organismen) im Sinne des Gentechnikrechts gelten sollten oder nicht. ${ }^{13}$ Der Europäische Gerichtshof (EuGH) urteilte 2018, ${ }^{14}$ dass es sich bei genomeditierten Pflanzen um GVO handele, wodurch die mittels Genome-Editing veränderten Pflanzen bzw. die auf ihnen basierenden Produkte $u$. a. aufwendige Zulassungsverfahren durchlaufen müssen und zudem kennzeichnungspflichtig sind. GVO sowie Lebensmittel und Futtermittel, die aus GVO bestehen, diese enthalten oder daraus hergestellt werden, müssen nach der EU-Verordnung (EG Nr. 1830/2003) mit dem Zusatz „gentechnisch verändert“ gekennzeichnet werden. Von der Kennzeichnungspflicht ausgenommen sind: 1) Produkte, die von Tieren stammen, die mit gentechnisch veränderten Futtermitteln gefüttert wurden, 2) Lebensmittel mit zufälligen oder technisch unvermeidbaren GVO-Spuren (bis max. $0,9 \%)$ und 3) Zusatzstoffe, die mithilfe von gentechnisch veränderten Mikroorganismen hergestellt werden.

Ein GVO im Sinne des Gentechnikgesetzes (GenTG) ist „ein Organismus, mit Ausnahme des Menschen, dessen genetisches Material in einer Weise verändert worden ist,

12 Für Anwendungsbeispiele und einen Überblick über CRISPR-Pflanzen weltweit siehe unter: https://www.gen-ethisches-netzwerk.de/index.php/genome-editing/crispr-pflanzen-weltweit [21.04.2021]; https://www.transgen.de/aktuell/2723.publikationen-genome-editing-crispr.html [21.04.2021.]; www.pflanzen-forschung-ethik.de [21.04.2021]. Zur Grünen Gentechnologie siehe Clemens, Kap. 7.

13 Zum Themenfeld Grüne Gentechnik und zu neuen Methoden siehe auch Clemens (Kap. 7), van den Daele/Broer (Kap. 21), Dederer (Kap. 22), Renn (Kap. 23) und Hampel et al. (Kap. 24).

14 EuGH, C-528/16, Confédération paysanne u. a., ECLI:EU:C:2018:583: 54. Für eine Einordnung des Urteils aus juristischer Sicht siehe Dederer, Kap. 22. 
wie sie unter natürlichen Bedingungen durch Kreuzen oder natürliche Rekombination nicht vorkommt“ ( 33 Abs. 3 GenTG). Auch mit Mutageneseverfahren wie Bestrahlung und chemischer Mutagenese behandelte Organismen gelten als GVO, sind jedoch von der strengen Regulierung ausgenommen, da diese Verfahren nach Angaben des Gerichts seit Langem in der Anwendung sind und als sicher gelten. ${ }^{15}$ Es gibt demnach eine unterschiedliche Beurteilung und rechtliche Behandlung von Mutageneseverfahren, die mit weitreichenden, kaum kontrollierbaren genetischen Änderungen verbunden sind, einerseits und CRISPR/Cas-Anwendungen ohne nachweisbare Rückstände andererseits. Viele sehen darin einen Widerspruch.

Das Urteil ist daher in der Wissenschaftsgemeinschaft umstritten. Naturwissenschaftliche Gremien protestierten gegen die Entscheidung des EuGH (siehe z. B. die Stellungnahme der Leopoldina et al., 2019; ähnlich Dederer, Kap. 22, sowie Clemens, Kap. 7, und van den Daele/Broer, Kap. 21). Der europäische Gerichtshof urteilte nicht der Sache nach, sondern nach dem Wortlaut der bestehenden EU-Verordnung. Zu einem anderen Urteil könnte er erst kommen, wenn in den zugrundeliegenden Gesetzen und ihren Definitionen der grundsätzlich neue Charakter des Genome-Editing adäquat berücksichtigt würde. Viele verbinden die Forderung nach einer sachgerechteren Urteilsbasis mit der Hoffnung auf eine breitere Akzeptanz der Anwendung der Technologie an Pflanzen (Grüne Gentechnologie) in der Bevölkerung und nicht zuletzt Möglichkeiten der Produktentwicklung und Vermarktung genomeditierter Pflanzen und anderer Organismen in Europa. ${ }^{16}$

Die juristische Debatte findet statt vor dem Hintergrund seit Langem kontrovers geführter Auseinandersetzungen um die Rolle von Gentechnik für die zukünftige Ernährungssicherung der Weltbevölkerung und für die globale Biodiversität. Zu den befürchteten Risiken der Anwendung solcher Verfahren gehören mögliche unbeabsichtigte Off-Target-Effekte, ${ }^{17}$ die Ausbreitung von Monokulturen von genetisch veränderten Pflanzen sowie Kontroversen um die kommerzielle Nutzung und den Schutz von einschlägigen Erfindungen durch Patente, die die Freiheit der Wissenschaft und ihre sinnvolle Anwendung versperren könnten. Dies sind vor allem ökologische, ethische und ökonomische Bedenken. Charakteristisch für den Diskurs zur Grünen Gentechno-

15 Vgl. hierzu den Wortlaut des Urteils unter: CURIA Dokumente (https://europa.eu/ [16.07.2021]), insbesondere Abschnitt 30.

16 Zur Wahrnehmung der Gentechnik in Medizin und Landwirtschaft in Deutschland siehe Hampel et al., Kap. 24.

17 Off-Target-Effekte treten allerdings auch bei den klassischen Mutageneseverfahren auf. Sie sind mit den heutigen NGS-Technologien ziemlich zuverlässig. Außerdem lassen sie sich durch Rückkreuzung weitgehend ausschließen. 
logie (vor allem im Unterschied zur Roten Gentechnologie, der medizinischen Anwendung am Menschen) ist der Umstand, dass der hypothetisch prognostizierte Nutzen (z. B. Herbizidresistenz, Stresstoleranz, Einsparung von Düngemitteln, Nährstoffanreicherung, der Beitrag zur Welternährung) von Kritiker*innen als nicht realistisch oder nicht hilfreich angesehen und somit anders bewertet wird, als bei (z. T. hypothetischen) Alternativen. Entsprechend fallen die speziellen Risiken der gentechnischen Methoden bei einer Abwägung schwerer ins Gewicht. In der Debatte spielt aber auch die übergreifende Frage eine große Rolle, welche Art von Landwirtschaft grundsätzlich favorisiert wird. Debatten um Grüne Gentechnik werden oft stellvertretend für den Diskurs um zukunftsfähige Leitbilder der Landwirtschaft - weitere Industrialisierung und Monopolisierung vs. biologische und kleinbäuerliche Landwirtschaft - geführt. Ist die Technologie mit dem Biolandbau vereinbar? Kann sie Teil einer nachhaltigen Strategie sein (siehe Renn, Kap. 23)? Welche Bedeutung wird Natürlichkeit beigemessen?18

Im Rahmen dieses Kapitels ist es nicht möglich, die lange und vielschichtige Debatte um die Grüne Gentechnologie umfassend zu beschreiben. Pragmatisch beschränken wir uns an dieser Stelle auf die Darstellung der Diskussion, ob genomeditierte Pflanzen tatsächlich als GVO eingestuft werden sollten oder nicht, wobei offenbleibt, ob es vielleicht einer eigenen Kategorie für diese bedarf. Das Argument für die Technologie besagt, dass sie, wenn sorgfältig und kritisch kontrolliert eingesetzt, gerade nicht zu genetischen Veränderungen führt, die im Sinne der vorliegenden Verordnungen nachweisbar niemals spontan auf natürlichem Wege hätten entstehen können. $\mathrm{Zu}$ den Gegenargumenten zählt (auf einer anderen Debattenebene), dass „Turbo-Gentechnik“ prinzipiell gerade wegen der möglichen, als „rasant“ dargestellten Beschleunigungen nicht beschritten werden sollte. Zudem würde sich eine Einführung der neuen Technologie über die verbreitete Ablehnung in der Bevölkerung (zumindest in Europa) hinwegsetzen. Strittig ist dabei, wie auch bei der herkömmlichen Gentechnik, ob eine Kennzeichnungspflicht dem Produkt gelten solle (Produktkennzeichnung) oder ob der Prozess der Herstellung (Prozesskennzeichnung) entscheidend sei (vgl. Jasanoff, 2005). Bei der Produktkennzeichnung ist die zentrale Frage, ob im Produkt selbst noch Bestandteile des gentechnischen Verfahrens nachweisbar sind oder nicht. Bei der Prozesskennzeichnung wäre dies egal, weil es allein auf die Herstellungsweise des Produktes ankommt. Schaut man sich nur das Produkt an, würden bestimmte genomeditierte Pflanzen (zumindest bei punktuellen naturnahen Genveränderungen) nicht unter die Kategorie GVO fallen, da diese i. d. R. nicht oder nur dann nachweisbar sind, wenn man

18 Mit den Vorstellungsbildern und dem Stellenwert von Natürlichkeit in den Debatten zur Grünen Gentechnologie beschäftigen sich u. a. Albrecht et al. (2017) sowie Dürnberger (2019). 
den Prozess der Herstellung kennt. ${ }^{19}$ Diese Auffassung führt dazu, dass bspw. in den USA bestimmte genomeditierte Pflanzen ohne besondere Auflagen angebaut und vertrieben werden dürfen. Stellt man jedoch den Prozess der Herstellung genomeditierter Pflanzen in den Vordergrund, wie dies seit den Anfängen des Gentechnikeinsatzes in der Landwirtschaft in Europa, im Gegensatz zur produktzentrierten Regulierung in den USA, gehandhabt worden ist, so bleibt der Einsatz von Gentechnologien auch im Falle kaum nachweisbarer punktueller Veränderungen für die Regulierung relevant. Aus dieser Perspektive liegt eine Kennzeichnung von genomeditierten Organismen als GVO nahe, auch wenn dies in Widerspruch zur Regulierung des sehr viel invasiveren und unberechenbareren Mutageneseverfahrens steht. Es ist aber auch nicht von der Hand zu weisen, dass die Wirkung einer Kennzeichnung als solche auf Einstellungen zur Gentechnik ein Stück weit spekulativ bleibt, aber die Kennzeichnungspflicht jedem und jeder Einzelnen die Möglichkeit lässt, sich für oder gegen den Kauf von genomeditierten Produkten zu entscheiden, wohingegen eine Nichtkennzeichnung eine solche individuelle Wahlmöglichkeit ausschließt. Kritiker*innen des EuGH-Urteils halten dem entgegen, dass sie nun nicht mehr die Wahl hätten, sich für den Kauf und Verkauf genomeditierter Produkte zu entscheiden, weil die Hürden für deren Markteinführung so hoch seien, dass die Vermarktbarkeit von und letztlich womöglich auch die Forschung an genomeditierten Pflanzen in Europa eingeschränkt sei (siehe van den Daele/Broer, Kap. 21; Dederer, Kap. 22).

\subsubsection{Ethische Aspekte von Keimbahnmodifikationen ${ }^{20}$}

Bei der Diskussion um den Einsatz von Genome-Editing am Menschen werden grundsätzlich Anwendungen zur somatischen Gentherapie von Eingriffen in die Keimbahn

19 Eine in der Fachzeitschrift Foods (Chhalliyil et al., 2020) vorgestellte Methode wird von Kritiker*innen des Genome-Editing als Nachweismethode angeführt, jedoch von Befürworter*innen als unzureichend beurteilt. Die Mutationen können mit der Methode nur dann nachgewiesen werden, wenn bekannt ist, welche Mutation wie eingeführt wurde. Eine reine Bestimmung der verwendeten Methode ohne diese Hintergrundinformation ist bislang nicht möglich. Für eine Diskussion der Möglichkeiten und Grenzen des Verfahrens siehe auch unter: https://www.bvl.bund.de/SharedDocs/ Fachmeldungen/06_gentechnik/2020/2020_09_09_Fa_Nachweismethode-genomeditierte-Pflanzen. html [21.04.2021]. Das Bundesamt für Verbraucherschutz und Lebensmittelsicherheit (BVL) geht davon aus, dass das Verfahren zwar Mutationen gezielt detektieren kann, aber offenbleibt, wie diese entstanden sind. Die in der genannten Studie untersuchten Rapslinien hält das BVL für anders entstanden.

20 Ein Teil der folgenden Überlegungen dieses Unterkapitels basiert auf der Analyse der IAG Gentechnologiebericht von 2015, die aktualisiert und ergänzt wurde. 
unterschieden (siehe u. a. Reich et al., 2015). Während Letztere an Keimzellen erfolgen, wodurch die genetische Veränderung auch auf folgende Generationen vererbt wird, zielt die somatische Gentherapie auf Körperzellen und ist somit per Definition nicht vererbbar (siehe Fehse, Kap. 6, zum aktuellen Sachstand). Die somatische Gentherapie findet i. d. R. in geborenen Menschen statt, während bei einer Keimbahnintervention vor allem Embryonen in vitro oder auch Keimzellen verändert werden. Die somatische Gentherapie wird seit den 1970er Jahren entwickelt. Dabei werden verschiedene Ansätze (siehe Fehse, Kap. 6) verfolgt, u. a.: 1) die Behandlung monogener Erbkrankheiten durch Einbringen einer funktionsfähigen Kopie des Gens bzw. in den letzten Jahren durch Korrektur des fehlerhaften Gens per Genome-Editing, 2) die Behandlung von Krebserkrankungen, z. B. durch Einbringen „toxischer“ („Suizid“-)Gene, mithilfe tumorzerstörender („onkolytischer“) Viren oder durch gezieltes „Scharfmachen“ von Immunzellen, 3) der Schutz von Zellen vor gefährlichen Infektionserregern wie z. B. $\mathrm{HIV}^{21}$

\section{Kontroverse um Genome-Editing der menschlichen Keimbahn}

In Bezug auf Keimbahninterventionen beim Menschen wird zwischen therapeutischen bzw. präventiven und auf Enhancement, also die Steigerung bestimmter Fähigkeiten oder die Herstellung bestimmter Merkmale, abzielenden Eingriffen unterschieden. Befürworter*innen von therapeutischen bzw. präventiven Keimbahnmodifikationen betonen deren Potenzial, Eltern mit bestimmten genetischen Merkmalen zu einem gesunden, biologisch verwandten Kind zu verhelfen. Sie argumentieren, dass die Vermeidung schwerer Krankheiten aus verschiedenen ethischen Positionen heraus wünschenswert, wenn nicht sogar moralisch geboten, und eine bewusst unterlassene Beseitigung eines schweren Krankheitsrisikos moralisch kaum zu begründen sei (Gyngell et al., 2017). Dabei sollte aber nicht übersehen werden, dass der medizinethische Imperativ des Heilens im Falle von Keimbahnmodifikationen, bei denen keine bereits existierenden Kranken geheilt werden, nicht greift (vgl. Andorno et al., 2020). Der Begriff „Keimbahntherapie“ ist ungenau, da er impliziert, dass es eine Entität gibt, die an einer Erkrankung leidet, während Keimzellen und frühe Embryonen weder Leid empfinden können noch sich bei ihnen überhaupt eine Krankheit manifestiert hat. Sie können lediglich bestimmte Gene tragen, die in der Zukunft zu einer Krankheit führen, weshalb Keimbahninterventionen eher in den Bereich der Prävention als den der Therapie fallen (siehe auch EGE, 2021: $28 \mathrm{ff}$.$) .$

21 Vgl. siehe unter: https://www.drze.de/im-blickpunkt/somatische-gentherapie [22.04.2021]. 
Allgemein anerkannt, auch seitens Befürworter*innen von Keimbahnmodifikationen, ist, dass das Verfahren noch nicht ausreichend ausgereift ist, um zum jetzigen Zeitpunkt Anwendung zu finden. Embryonen und deren mögliche Nachkommen einem unkalkulierbaren Risiko auszusetzen, verstößt nach verbreiteter Auffassung grundsätzlich gegen das medizinethische Prinzip des Nicht-Schadens. Neben der Sicherheit sind weitere strittige Punkte, die von den einzelnen Diskutant*innen unterschiedlich gewichtet werden, dass für die Entwicklung von Keimbahnmodifikationen die umstrittene „verbrauchende“ Embryonenforschung notwendig ist und dass ein Eingriff in die Existenz eines zukünftigen Menschen vorgenommen wird, der in diesen prinzipiell nicht einwilligen kann („Recht auf Selbstbestimmung“ bzw. Autonomie); weder in die nicht kalkulierbaren Risiken, noch in die möglicherweise erforderliche lebenslange medizinische (Nach-)Kontrolle und Versorgung (siehe u. a. zur Einwilligung auch Alex/ Winkler, Kap. 13). Der Eingriff wird zudem von einigen als Würdeverletzung gewertet. Darunter wird zum einen eine Instrumentalisierung des Embryos verstanden. Das dürfte insbesondere dann der Fall sein, wenn Ziel des Eingriffs nicht die Vermeidung schwerer Krankheit, sondern die Erzeugung von Kindern mit Wunscheigenschaften der Eltern ist („Recht auf eine offene Zukunft“) oder gar von Menschen mit bestimmten Fähigkeiten und militärisch oder anderweitig nutzbaren Eigenschaften durch totalitäre Regime. Zum anderen wird eine Würdeverletzung der Menschheit an sich basierend auf einem abstrakten Menschenbild angesprochen. Hierbei wird die (genetische) Identität der menschlichen Spezies als Wert angesehen. Eng verbunden mit diesem Einwand gegen Keimbahnmodifikationen sind Natürlichkeitsargumente, die auf die Natur, genauer die menschliche Natur, als Wert verweisen und daraus eine generelle Unverfügbarkeit der genetischen Ausstattung ableiten. In einer religiös gewendeten Version wird auch von „unerlaubtem Gott spielen“ durch „Eingriffe in die Schöpfung“ gesprochen. Allerdings wären unter diesen Gesichtspunkten auch potenziell keimbahnschädigende Therapien wie Bestrahlung oder Chemotherapie unzulässig. ${ }^{22}$

Darüber hinaus gibt es Bedenken, dass es durch die Zulassung und den Einsatz von Keimbahnmodifikationen zu einer schiefen Ebene, insbesondere hin zu Eugenik und

22 Auf konzeptuelle und weitere Probleme der Bestimmung und Inwertsetzung von Natur und Natürlichkeit kann hier nicht eingegangen werden. 
Diskriminierung, kommen könnte (sog. Schiefe-Ebene- oder Dammbruchargumente). ${ }^{23}$ Es wird die Befürchtung zum Ausdruck gebracht, dass, wenn die Methode erst einmal für medizinische Zwecke etabliert sei, ihr Einsatz für nichtmedizinische Zwecke der Fähigkeitssteigerung (Enhancement) oder der Herstellung von Menschen mit bestimmten Eigenschaften nicht mehr aufgehalten werden könne. ${ }^{24}$ Weiter verkompliziert wird die Lage dadurch, dass Unterscheidungen wie Therapie und Enhancement sowie auch grundsätzlich die zwischen Gesundheit und Krankheit unscharf sind, also Übergänge und Graubereiche aufweisen. Im Zusammenhang damit wurde verschiedentlich die Befürchtung geäußert, es könne mit der Etablierung von Keimbahnmodifikationen zu einer „neuen Eugenik“ oder einer „Eugenik von unten“ kommen (kritisch zum Eugenikbegriff im Kontext des Genome-Editing siehe Ranisch, 2018). Diskutiert wird auch, ob Keimbahninterventionen künftig, wie ihre Befürworter*innen betonen, einen Beitrag zu „reproduktiver Wahlfreiheit“ leisten können oder ob sie eher, wie Kritiker*innen entgegenhalten, zu einer Erhöhung gesellschaftlichen Druckes zur Optimierung des eigenen Nachwuchses führen. Bedenken wurden insbesondere dahingehend geäußert, ob es durch eine Implementierung von Keimbahnmodifikationen zu einer weiteren Stigmatisierung von Menschen mit Behinderung kommen könnte und ob sich der gesellschaftlich vorherrschende defizitorientierte Blick auf Behinderung weiter verschärft (GeN, 2019: 6). Zudem wurde die Sorge geäußert, dass es im Falle einer erfolgreichen Entwicklung von Keimbahninterventionen zu einer Verstärkung gesellschaftlicher Ungleichgewichte kommen könnte, bspw. indem ohnehin durch Einkommen und andere Faktoren besser gestellte Eltern ihren Nachwuchs zusätzlich noch genetisch optimieren. Allgemein als wünschenswert betrachtete Eigenschaften wie Intelligenz oder Stärke beruhen jedoch auf sehr komplexen genetischen und anderen biologischen und sozialen Bedingungen, die sich absehbar nicht durch Eingriffe in das Genom nach Wunsch herstellen lassen. Grundsätzlich sind jedoch Fragen der Allokation von Mitteln im Gesundheitswesen und Zugangsmöglichkeiten zu neuen therapeutischen Ansätzen

23 Dammbruchargumente kritisieren nicht (wie z. B. Menschenwürdeargumente) die Anwendung von Keimbahninterventionen an sich als ethisch inakzeptabel, sondern sie sprechen sich gegen eine Zulassung aus, aufgrund von angenommenen und ihrerseits ethisch inakzeptablen (moralisch-rechtlichen oder sozialen) Konsequenzen einer solchen Zulassung. Ihre meist kritisierte Schwachstelle liegt darin, dass manche Formen von Dammbruchargumenten bloße Befürchtungen einer eintretenden Entwicklung vortragen, ohne Belege für die vermutete Entwicklung oder wenigstens deren Plausibilität vorzulegen.

24 Häufig ist auch die Zulassung nur für schwere monogene Erbkrankheiten im Gespräch, wobei die schiefe Ebene dann bereits bei der Zulassung für weniger schwere Krankheiten betreten wäre. Die Beurteilungskriterien und -instanzen, um die Schwere von Krankheiten und Angemessenheit von Keimbahninterventionen zu bestimmen, bleiben meist unklar. 
unabhängig vom Einkommen ganz zentral für eine sozial gerechte Ausgestaltung der klinischen Translation von Genome-Editing bzw. der Implementierung von Gentherapien (zum Kosten- und Gerechtigkeitsproblem im Kontext der somatischen Gentherapie siehe Fehse, Kap. 6).

Gegen die Inkaufnahme der (bislang unkalkulierbaren) Risiken von Keimbahninterventionen wird mit der Existenz von sicheren, bereits langjährig in der Anwendung befindlichen Alternativen wie der Präimplantationsdiagnostik (PID) zur Vermeidung schwerer Erbkrankheiten argumentiert. ${ }^{25}$ Es gebe damit grundsätzlich keine medizinische Indikation für eine Keimbahnmodifikation. Bei einer PID werden nach einer künstlichen Befruchtung mehrere Embryonen einem genetischen Test unterzogen und auf Basis des Ergebnisses diejenigen ausgewählt, die ein bestimmtes Merkmal wie etwa die Anlage zu einer schweren Erbkrankheit nicht tragen. Diese werden dann der zukünftigen Mutter in die Gebärmutter übertragen, während die anderen verworfen werden. Die Untersuchung hat nach aktuellem Erkenntnisstand keine schädigenden Auswirkungen auf die übertragenen Embryonen (die über die Risiken der IVF hinausgehen). Die PID ist nicht nur eine Alternative zur Keimbahnmodifikation, sondern auch notwendig mit dieser verbunden: Eingangs könnte eine PID notwendig sein, um diejenigen Embryonen zu identifizieren, die behandelt werden müssen; und eine zweite PID muss nach der erfolgten Genomeditierung und vor der Einpflanzung des Embryos in die Gebärmutter überprüfen, ob die Behandlung erfolgreich war. Da man sowieso eine PID durchführt, könnte man, so das Argument, zur Vermeidung der meisten schweren Erbkrankheiten auch gleich auf eine Keimbahnmodifikation verzichten und die durch die PID identifizierten Embryonen ohne Krankheitsrisiko verwenden. Dagegen wird eingewandt, dass es doch besser sei, Embryonen zu heilen als sie zu verwerfen ${ }^{26}$ oder bewusst Entwicklungsstörungen des Embryos, die nur durch eine Keimbahnmodifikation verhinderbar wären, in Kauf zu nehmen. Denn es gibt äußerst seltene Konstellationen, in denen Eltern keine nicht betroffenen Embryonen zur Verfügung haben. ${ }^{27}$ Gerade angesichts der Seltenheit dieser Fälle wird allerdings die Verhältnismäßigkeit der Risiken einer Keimbahnmodifikation infrage gestellt (EGE, 2021: 35).

25 Die PID ist in Deutschland seit 2014 zur Vermeidung schwerer Erbkrankheiten erlaubt, setzt aber die Zustimmung einer Ethikkommission des eigenen Bundeslands voraus, die jeweils den Einzelfall abwägt. Hierbei kann es je nach Bundesland zu unterschiedlichen Abwägungsentscheidungen kommen.

26 Allerdings werden nach dem Stand der Technik auch beim Keimbahn-Editing Embryonen per PID verworfen, bei denen der Eingriff nicht erfolgreich war.

27 Etwa, wenn beide Eltern in beiden Genkopien die Anlagen für eine rezessive Erbkrankheit tragen (sie also reinerbig/homozygot in Bezug auf dieses Merkmal sind) oder wenn ein/e Partner*in in beiden Genkopien die Anlage für eine dominante Erbkrankheit trägt. 
Außer Acht gelassen wird in den Debatten mitunter, dass es mit Adoption oder Pflegeelternschaft in den meisten Ländern für die Erfüllung eines Kinderwunsches auch soziale Alternativen zum biologisch verwandten Nachwuchs gibt. Grundsätzlich kann hinterfragt werden, warum der genetischen Verwandtschaft eine solch große Bedeutung beigemessen wird wie gegenwärtig in westlichen Gesellschaften und darüber hinaus. Eine kritische Untersuchung der Entstehung und Formung entsprechender Bedürfnisse und der gesellschaftlichen Angebote zu ihrer Befriedigung in Auseinandersetzung mit gesellschaftlichen Machtverhältnissen, Ideologien und Normalitätsstandards wäre hier aufschlussreich. ${ }^{28}$ Kritiker*innen weisen zudem auf die Gefahr einer verstärkten Kommodifizierung, also eines Zur-Ware-Werdens des menschlichen Körpers im Zuge der Entwicklung und Anwendung der Technik hin.

Wie umgehen mit den technischen Möglichkeiten? Handlungsempfehlungen zum Genome-Editing am Menschen

Die Handlungsempfehlungen der IAG von 2015 (Reich et al.) in Bezug auf die medizinische Nutzung von Genome-Editing sind im Prinzip immer noch aktuell: Die ethische Vertretbarkeit des Genome-Editing zu medizinischen Zwecken hänge vom Ziel und Kontext ab, es solle keine pauschale Verurteilung der Technologie geben. Die Erforschung der Methoden wird seitens der Verfasser der Stellungnahme grundsätzlich unterstützt, für Keimbahnmodifikationen fordern sie aber ein Moratorium, d. h. einen zeitlich befristeten Verzicht auf den Einsatz, um währenddessen die offenen ethischen, rechtlichen und auch biologischen Fragen zu klären. Ein Moratorium für Keimbahneingriffe wurde in den letzten Jahren mehrfach gefordert, auch von namhaften Forscher*innen in Science (Baltimore et al., 2015) und Nature (Lander et al., 2019), darunter die Nobelpreisträgerinnen Jennifer Doudna und Emmanunelle Charpentier, sowie von Ethikgremien wie dem Deutschen Ethikrat. ${ }^{29}$ Neben dem Wissenszugewinn wurde argumentiert, dass es der Gesellschaft Zeit für eine politische Auseinandersetzung und Willensbildung darüber verschaffe, ob, zu welchen Zwecken und in welchem Rahmen

28 Zum Desiderat gesellschaftskritischer Forschungsansätze in diesen Zusammenhängen vgl. Lettow (2011: $93 \mathrm{f}$.).

29 Dem Deutschen Ethikrat zufolge sind Keimbahnmodifikationen zur Vermeidung erblicher Erkrankungen in Zukunft grundsätzlich zulässig, sofern verschiedene Bedingungen und Kriterien erfüllt sind. Alle anderen Anwendungen erforderten auch zukünftig eine Einzelfallprüfung. Da der Deutsche Ethikrat die Bedingungen für eine hinreichend sichere und wirksame Anwendung noch längst nicht für erfüllt hält, fordert auch er „ein internationales Moratorium für die klinische Anwendung von Keimbahnmodifikationen beim Menschen und empfiehlt dem Deutschen Bundestag und der Bundesregierung, auf eine verbindliche internationale Vereinbarung, vorzugsweise unter der Ägide der Vereinten Nationen, hinzuwirken“ (Deutscher Ethikrat, 2019: 232). 
das Erbgut künftiger Generationen mittels Keimbahnmodifikationen verändert werden dürfe. Schließlich gehe es dabei nicht zuletzt um grundsätzliche Fragen des Menschenbildes und der Generationenverhältnisse, wie u. a. Christiane Woopen betonte. ${ }^{30}$

Die internationale Diskussion hat sich seitdem jedoch wesentlich verschoben: Wurde ursprünglich darüber diskutiert, ob Keimbahnmodifikationen bei schweren Krankheiten grundsätzlich erlaubt oder verboten sein sollten, wobei die Veränderung der menschlichen Keimbahn aufgrund der unabsehbaren und möglicherweise irreversiblen Folgen für künftige Generationen lange als Tabu galt und in der Oviedo-Konvention des Europarates (Council of Europe, 1997/1999) sowie vielen Ländern verboten ist, werden gegenwärtig zunehmend Bedingungen diskutiert, die erfüllt sein müssen, damit ein Eingriff als gerechtfertigt gelten kann. Entsprechend hat sich auch der Schwerpunkt der ethischen Debatte von anfänglichen prinzipiellen Einwänden gegen Keimbahninterventionen (auch im Forschungskontext) wie Menschenwürde-, Natürlichkeits- und Dammbruchargumenten verlagert hin zu Sicherheitsargumenten im Reproduktionskontext. Bereits in seiner Ad-hoc-Empfehlung von 2017 stellte der Deutsche Ethikrat fest, dass es eine absolute Schutzwürdigkeit der Keimbahn nicht gebe. ${ }^{31}$ Genome-Editing an menschlichen Keimzellen nicht weiter zu erforschen, fordern nur noch wenige Organisationen (bspw. das Genethische Netzwerk; GeN, 2019). Als neuer Konsens erscheint hingegen vielen Wissenschaftsorganisationen und Ethikräten nicht nur die Erforschung, sondern auch die Anwendung von Keimbahnmodifikationen unter bestimmten Bedingungen akzeptabel. Als Kriterien nennen entsprechende Stellungnahmen häufig allen voran die technische Sicherheit und Wirksamkeit, die medizinische Notwendigkeit bzw. Alternativlosigkeit, einen großen erwartbaren Nutzen, die aufgeklärte Einwilligung der Eltern, einen gesellschaftlichen Konsens bzgl. der Wünschbarkeit, Formen und Grenzen des Einsatzes sowie einen angemessenen rechtlichen Rahmen. ${ }^{32}$ Allerdings bleibt unklar, wie genau diese Ansprüche eingelöst und bspw. die technische Sicherheit oder der Nutzen bestimmt werden können und wer darüber auf Basis welcher Kriterien entscheiden sollte. Mit den wissenschaftlichen Fragen, die für die (auf wissenschaftlich-technische Risiken bezogene) Vertretbarkeit einer Keim-

30 Siehe unter: https://www.sciencemediacenter.de/alle-angebote/research-in-context/details/ news/globales-moratorium-fuer-keimbahneingriffe-mittels-genome-editing/ [21.04.2021]. Zur Technikfolgenabschätzung von CRISPR in der Keimbahn siehe auch Hardt (2019).

31 Siehe unter: https://www.ethikrat.org/publikationen/publikationsdetail/?tx_wwt3shop_ detail\%5Bproduct\%5D=19\&tx_wwt3shop_detail\%5Baction\%5D=index\&tx_wwt3shop_detail\%5Bcontroller\%5D=Products\&cHash=e197afc2a9431bdc3602d100e226cbc9 [23.08.2021].

32 Die Keimbahnmodifikation wird international u. a. in folgenden Stellungnahmen diskutiert: Nuffield Council on Bioethics (2018); Deutscher Ethikrat (2019); GeN (2019); TA-Swiss (2019); NASEM (2020); WHO (2020); EGE (2021). 
bahnmodifikation mittels CRISPR/Cas geklärt werden müssen, sowie mit Möglichkeiten einer sicheren klinischen Translation, haben sich die Wissenschaftsakademien in ihrer gemeinsamen Stellungnahme ausführlich beschäftigt (NASEM, 2020). Zwar lässt sich durch die von NASEM empfohlenen Methoden wie Tierversuche und Forschungen am menschlichen Embryo sowie den Rekurs auf den Kenntnisstand zu künstlicher Befruchtung und somatischer Gentherapie Wissen und ein besseres Verständnis von möglichen Auswirkungen von Genome-Editing in der Keimbahn gewinnen, jedoch bleibt es bei der vorklinischen Evidenz - das Stufenmodell, das bei klinischen Versuchen zur Überprüfung neuer Medikamente und Impfstoffe üblich ist, lässt sich hier nicht anwenden. Übliche Schritte und Sicherheitsvorkehrungen bei Medikamentenstudien sind also nur in Grenzen auf Keimbahnmodifikationen übertragbar. Deshalb wird auch davon gesprochen, dass es sich notwendigerweise bei den ersten Anwendungen zu reproduktiven Zwecken um Menschenversuche handele.

Gefordert wird aber auch, den Blick nicht auf wissenschaftlich-technische Sicherheitsfragen zu verengen, sondern dezidiert die ethischen und gesellschaftlichen Dimensionen einer Keimbahnmodifikation in den Blick zu nehmen. ${ }^{33}$ Für die ethische Beurteilung von Keimbahnmodifikationen mittels CRISPR/Cas bringen die verschiedenen Stellungnahmen unterschiedliche ethische Prinzipien ins Spiel. So plädiert der britische Nuffield Council on Bioethics (2018) für eine Orientierung an den Prinzipien des Wohlergehens der künftigen Person sowie der Solidarität und sozialen Gerechtigkeit, wobei er durchaus auch den Einsatz von Keimbahnmodifikationen für Enhancement und andere Zwecke für vertretbar hält, solange die genannten Prinzipien und bestimmte Sicherheitsvorkehrungen gewahrt seien. Der Deutsche Ethikrat hingegen diskutiert eine Vielzahl an ethischen Prinzipien: Menschenwürde, Lebens- und Integritätsschutz, Freiheit, Natürlichkeit, Schädigungsvermeidung und Wohltätigkeit, Gerechtigkeit,

33 Siehe die Gemeinsame Erklärung des Comité Consultatif National d'Éthique, des Deutschen Ethikrates und des Nuffield Council on Bioethics unter: https://www.ethikrat.org/publikationen/publikationsdetail/?tx_wwt3shop_detail\%5Bproduct\%5D=128\&tx_wwt3shop_detail\%5Baction\%5D=index\&tx_wwt3shop_detail\%5Bcontroller\%5D=Products\&cHash=bb50455bee82c95fbbaa191557da2b5a [23.08.2021] sowie EGE, 2021: 20: „The ,safe enough' narrative purports that it is enough for a given level of safety to be reached in order for a technology to be rolled out unhindered, and limits reflections on ethics and governance to considerations about safety“. Zu Deutsch: Das Narrativ ,sicher genug' behauptet, dass es ausreicht, ein bestimmtes Sicherheitsniveau zu erreichen, damit eine Technologie ungehindert eingeführt werden kann, und beschränkt die Reflexionen über Ethik und Governance auf Überlegungen zur Sicherheit. 
Solidarität sowie Verantwortung. Es wird zudem ein Entscheidungsbaum vorgeschlagen, der diese Komplexität durch sechs aufeinander folgende Fragen ergänzt. ${ }^{34}$

Internationale Regulierungen wurden auch zum Einsatz von Genome-Editing in anderen Kontexten gefordert, bspw. dem der Do-it-yourself-Biologie (vgl. EGE, 2021), woran verschiedene Gremien wie das der WHO arbeiten. Fast allen Stellungnahmen und Empfehlungen gemeinsam sind Forderungen nach neuen Formen und Institutionen gesamtgesellschaftlicher Auseinandersetzung aufgrund der umfassenden Einsatzmöglichkeiten des Genome-Editing sowie der langfristigen und kaum abschätzbaren Auswirkungen insbesondere der reproduktiven Anwendung zur Veränderung der menschlichen Keimbahn. Studien zur Wahrnehmung von Keimbahnmodifikationen in der Bevölkerung spiegeln jedoch eine gewisse Ambiguität in ihrer Bewertung wider, je nachdem, ob die Befragung die medizinische Wirkung oder die mit der Anwendung verbundenen Risiken in den Vordergrund stellt (vgl. Hampel et al., Kap. 24). Auch vor dem Hintergrund dessen, stellt sich die Frage, wie die von vielen Seiten geforderte Einbeziehung der gesamten Gesellschaft(en weltweit) angemessen gestaltet sein kann (siehe hierzu Spotlight Leßmöllmann, Kap. 14 sowie Rosemann et al., 2020). Besonders prominent war der Vorschlag zur Einrichtung eines verschiedenste gesellschaftliche Gruppen einbeziehenden Global Observatory (Jasanoff/Hurlbut, 2018), was weithin als wichtiger und unterstützenswerter Vorstoß anerkannt worden ist (siehe EGE, 2021; Hucho, Kap. 2).

\section{Der Fall He Jiankui: die chinesischen Zwillingsmädchen}

Ausgelöst wurde die Veröffentlichung der neueren Stellungnahmen zu Keimbahnmodifikationen mittels Genome-Editing durch deren erste Anwendung im Reproduktionskontext durch Jiankui He in China, die im November 2018 bekannt wurde und zu einem weltweiten Aufschrei führte. Es bestand Konsens innerhalb der Wissenschaftsgemeinschaft, dass es sich bei dem Eingriff um Menschenversuche gehandelt habe, die zum damaligen (und auch zum heutigen) Zeitpunkt zu früh und unverantwortlich gewesen seien. Der Umstand, dass ein solcher Eingriff im Reproduktionskontext vorgenommen worden war, führte die Diskussion bei aller Verurteilung allerdings dazu, dass aus-

34 „Der Entscheidungsbaum stellt sechs zentrale Fragen, die nach Auffassung des Deutschen Ethikrates auf einem möglichen Weg zu einer Praxis von Keimbahneingriffen am Menschen zu beantworten sind: >> Frage 1: Ist die menschliche Keimbahn unantastbar? >> Frage 2: Darf/soll man das Ziel, in die Keimbahn einzugreifen, verfolgen? >> Frage 3: Darf/soll verbrauchende Forschung an menschlichen Embryonen in vitro durchgeführt werden? >> Frage 4: Darf/soll man auf Ergebnisse der verbrauchenden Embryonenforschung Dritter zurückgreifen, auch wenn man solche Forschung selbst ablehnt? >> Frage 5: Darf/soll man zur klinischen Forschung übergehen? >> Frage 6: Darf/soll man Keimbahneingriffe zur Vermeidung monogener Krankheitsanlagen (6.1), zur Reduzierung von Krankheitsrisiken (6.2) oder zu Enhancement-Zwecken (6.3) durchführen“ (Deutscher Ethikrat, 2019: 45). 
buchstabiert wurde, welche Kriterien denn erfüllt sein müssten, damit ein derartiger Eingriff als gerechtfertigt gelten könne (siehe oben). Der Biophysiker Jiankui He von der Southern University of Science and Technology in Shenzhen (China) veröffentlichte seine Ergebnisse nicht in einer angesehenen internationalen Fachzeitschrift mit einem wissenschaftlichen Begutachtungsverfahren zur Überprüfung und Transparenz der Ergebnisse, sondern gab die Versuche zunächst gegenüber einer Nachrichtenagentur und auf YouTube bekannt. ${ }^{35}$ So war zunächst unklar, was genau er gemacht hatte und ob es nur ein Gerücht sei. Er hatte aber tatsächlich erstmalig die Technologie an durch IVF gezeugten Embryonen eingesetzt, die anschließend auf die Mutter übertragen wurden und sich bis zur Geburt weiterentwickelten. Es handelt sich um Zwillingsmädchen mit den Decknamen Lulu und Nana. Ziel des Eingriffs war die Veränderung eines Gens für einen Rezeptor (CCR5) im Immunsystem, der bekannter Weise bei einer Virusexposition einen weitgehenden Schutz vor einer HIV-Infektion verleiht. ${ }^{36}$ Der Vater der Mädchen war HIV-positiv, womit der Einsatz von CRISPR/Cas vonseiten der involvierten Forscher*innen gerechtfertigt wurde. Allerdings kann eine direkte Übertragung des HI-Virus vom Vater auf die Kinder während der Schwangerschaft effektiv ausgeschlossen werden; selbst wenn der Vater die Mutter infizieren würde, könnten die Embryonen/Föten noch sehr gut geschützt werden. Auch im späteren Leben wäre eine Ansteckung vom Vater auf die Kinder bei entsprechenden Vorsichtsmaßnahmen ohne weiteres verhinderbar. Daher bestand für das Editing keine medizinische Notwendigkeit. Die Aufklärung der Eltern hierüber war mangelhaft. Kurz darauf wurde auch die Geburt eines dritten von Jiankui He genetisch veränderten Kindes bestätigt (vermutlich im Sommer 2019).

Von verschiedener Seite wurde He vorgeworfen, dass seine Daten zeigten, dass es ihm nicht gelungen sei, die natürlich vorkommende, HIV-Resistenz vermittelnde CCR5 32 Mutation (Liu, 1996) zu reproduzieren. ${ }^{37}$ Allerdings muss man fairerweise feststellen, dass er das weder intendiert noch behauptet hatte. Stattdessen ging es ihm um eine effiziente Zerstörung (Knockout) des CCR5-Leserahmens, ähnlich wie das in Studien zur somatischen Gentherapie versucht wird. ${ }^{38}$ In einer Reihe von Studien zur somatischen Gentherapie konnte gezeigt werden, dass dieser Ansatz prinzipiell erlaubt,

35 Siehe unter: https://www.youtube.com/watch?v=thovnOmFltc [21.04.2021]. Mit dem späteren Versuch einer Veröffentlichung in einer Fachzeitschrift scheiterte He, allerdings wurde sein Manuskript geleakt (Siehe unter: https://topic.echemi.com/a/he-jiankuis-manuscript-was-exposed-revealing-the-unknown-secret-of-gene-editor-baby_5e5495f2d515cd75583c03e3.html [16.08.2021]).

36 Zur Biologie der Versuche siehe Kronberg (2019) und Regalado (2019).

37 Der Schutz vor HIV ist nicht komplett, da es neben dem häufigeren CCR5-tropen Virus auch eine Virusvariante („,CXCR4-trop“) gibt, die einen anderen Chemokinrezeptor (CXCR4) als HIV-Korezeptor benutzt. 38 Vgl. Fehse/Abramowski-Mock (2021). 
genetisch modifizierte Zellen vor HIV zu schützen (z. B. Tebas et al., 2014). Auch wenn daher davon auszugehen ist, dass das komplette Fehlen der CCR5 Expression (bei einem der beiden geborenen Mädchen) einen weitgehenden Schutz vor HIV vermittelt, lassen sich mögliche Nebenwirkungen der Manipulation nicht vorhersagen. Dies betrifft $u$. a. mögliche Off-Target-Effekte, auch wenn die von He vorgelegten Daten keine Off-TargetAktivität zeigen. Beide Mädchen weisen unterschiedliche Veränderungen in den beiden CCR5-Allelen auf, bei einem der beiden ist nur eines der beiden Allele modifiziert worden (Regalado, 2019), sodass nur ein eingeschränkter Schutz zu erwarten ist. Menschen, die eine homozygote CCR5 32 Mutation tragen, sind, wie gesagt, weitgehend vor HIV geschützt und trotz des fehlenden Gens gesund. Allerdings zeigen sie eine erhöhte Anfälligkeit gegenüber bestimmten Infektionserregern, wie z. B. dem West-Nil-Virus (Glass, 2005). Insgesamt lässt sich konstatieren, dass der von He verfolgte Ansatz aus medizinischer Sicht keinerlei Sinn ergibt - das Ziel bestand darin, dass bereits minimale und durch geeignete Prävention weitgehend ausschließbare Risiko einer HIVInfektion (die zudem heute gut behandelbar ist) weiter zu verringern. Dafür wurden konkrete (erhöhtes Infektionsrisiko gegenüber anderen Erregern) wie auch eine Reihe unbekannter Risiken (Off-Target-, epigenetische Effekte) in Kauf genommen.

Jiankui Hes Forschung wurde nach der Bekanntgabe sofort gestoppt. Im Januar 2019 stellte eine staatliche Untersuchungskommission fest, dass sich der Forscher des Betrugs und des wissenschaftlichen Fehlverhaltens schuldig gemacht habe. Er wurde darauf von der Southern University of Science and Technology suspendiert. Ende 2019 verurteilte ein chinesisches Gericht Jiankui He zu drei Jahren Haft und einer Geldstrafe in Höhe von 3 Mio. Yuan (380.000 €). Zwei beteiligte Kollegen erhielten geringere Strafen. Es war zunächst unklar, ob He das chinesische Gesetz gebrochen hatte. Da es in China zu diesem Zeitpunkt kein Verbot von Keimbahnmodifikationen gab, wurden die Forscher aufgrund anderer Gesetzesübertretungen, wie der Umgehung der Genehmigung durch eine Ethikkommission und der Gefährdung der Sicherheit von Patient*innen, verurteilt. In der Urteilsbegründung wurde von illegalen medizinischen Eingriffen gesprochen und eine fehlende ärztliche Qualifikation des Forschungsteams bemängelt. Der Vorfall wurde als absichtlicher Verstoß gegen nationale Vorschriften für wissenschaftliche Forschung gewertet. In der Öffentlichkeit wurde He als verrückter Einzelkämpfer dargestellt, doch es gibt Hinweise darauf, dass ein ganzes Netzwerk von Mitwissenden auch in anderen Ländern seine Versuche nicht verhindert hat (Cohen, 2019). 


\subsection{Einzelzellanalyse ${ }^{39}$}

\subsubsection{Einführung und Anwendungspotenziale}

Einzelzellanalysen sind ein schnell wachsender Forschungsbereich mit einem breiten Anwendungsspektrum und großem Potenzial für die Biologie in ihrer ganzen Bandbreite, von der Zellbiologie und Entwicklungsbiologie über Physiologie und Pathologie bis hin zu Taxonomie und Ökologie (Walter/Gasparoni, 2019: 19). Auch für die Medizin sind ihre Erkenntnisse unmittelbar relevant (Aschenbrenner et al., 2019).

Der erwachsene Mensch besteht aus einer unvorstellbar großen Zahl unterschiedlicher Zellen (insgesamt ca. 38 Bio., bislang eingeteilt in mehr als 200 verschiedene Zelltypen), deren Zustand und Funktionen sich im Verlauf des Lebens ändern. Auch Alterungsprozesse und Krankheiten haben oft Ursachen und Auswirkungen auf zellulärer Ebene. Die moderne Einzelzellanalytik erlaubt erstmals die Analyse nicht nur verschiedener Zellpopulationen, Gewebe oder anderer Zellgemische wie bisher, sondern tatsächlich einzelner Zellen. Statt Durchschnittswerten ermöglichen diese Einzelzelldaten tiefe Einblicke in die molekulare Funktionsweise der untersuchten Zellen. Ihre Ergebnisse bergen neue Möglichkeiten nicht nur für die Grundlagenforschung in den Lebenswissenschaften, sondern auch für die Biotechnologie, Pharmaforschung und die medizinische Praxis. So können Zellen von Patient*innen untersucht und mit Zellen gesunder Proband*innen verglichen werden, um individuelle Krankheitshintergründe zu erforschen. Es kann auch getestet werden, wie bestimmte Zellen im Körper auf Medikamente ansprechen. Damit ermöglicht die Einzelzellanalyse einen wichtigen Schritt hin zu einer personalisierten Medizin.

$\mathrm{Zu}$ den neuen Möglichkeiten haben technologische Entwicklungen wie das NextGeneration-Sequencing (siehe Mundlos, Kap. 4) beigetragen, die so umfunktioniert

39 Die folgenden Ausführungen basieren auf der Stellungnahme „Einzelzellanalyse in Forschung und Medizin“ (Walter/Schickl, 2019), insbesondere den Kernaussagen der IAG Gentechnologiebericht (Walter et al., 2019), die lediglich aktualisiert wurden. Sie fassen den Inhalt der Stellungnahme zusammen und aktualisieren den Sachstand da, wo sich seit 2019 Neuerungen ergeben haben. Das Thema kann hier nur angerissen und in seiner Bedeutung für die Forschung eingeordnet werden. Für eine umfassende Darstellung des Themas sei auf die Stellungnahme von 2019 verwiesen. Die Abschnitte zur Technik und zur Ethik wurden fast wortgleich übernommen, da sie noch den aktuellen Sachstand darstellen. 
wurden, dass damit etwa auch Genexpressionsprofile ${ }^{40}$ erfasst werden können. Die Interpretation von Einzelzelldaten kann neben der Genomebene (,genomics“) daher inzwischen auch auf ganz anderen Ebenen erfolgen, die mit sogenannten Omics-Technologien erforscht werden. ${ }^{41}$ Dies ist wichtig, weil die Sequenz von Genomen in den Zellen erst interpretiert und über Moleküle, die die Zellfunktion steuern, wie unterschiedliche RNAs und Proteine, in Zellfunktionen übersetzt werden muss (siehe Mundlos, Kap. 4). Zu den Omics-Technologien gehören etwa die Analyse der Gesamtheit der RNA-Transkripte (,transcriptomics“), der Proteine (,proteomics“), der Stoffwechselprodukte (,metabolomics“), der Lipide („lipidomics“) und der epigenetischen Zustände („epigenomics“). Mithilfe dieser Technologien können komplexe Vorgänge in der Zelle untersucht werden. Schwierigkeiten bereitet jedoch derzeit noch, die dabei anfallenden verschiedenen Arten von Daten miteinander in Beziehung zu setzen (siehe unten).

Die moderne automatisierte Einzelzellanalytik im Hochdurchsatzverfahren erlaubt die gleichzeitige Analyse mehrerer Mio. Zellen. Dadurch können auch sehr komplexe Prozesse analysiert werden, wie etwa die Entwicklung von Organen. ${ }^{42}$ Ergänzt durch bildgebende und spezielle PCR-Verfahren ist es dabei auch möglich, die räumliche Zuordnung einzelner Zellen im Organ oder Gewebe mit zu erfassen. ${ }^{43}$ Durch Einzelzellanalysen können zelluläre Veränderungen bei chronischen Erkrankungen sowie die Auswirkungen genetischer Erkrankungen auf einzelne Zelltypen systematisch erfasst und analysiert werden. „Die zelluläre Heterogenität innerhalb von Geweben war immer ein großes Hindernis im Verständnis und in der Behandlung von Krankheiten wie Krebs, chronisch entzündlichen Erkrankungen, Autoimmunerkrankungen, Infektionen oder neurodegenerativen Erkrankungen“ (Aschenbrenner et al., 2019: 38). Auch die Untersuchung individueller, patientenspezifischer Tumore für eine personalisierte,

40 Genexpressionsprofile zeigen die Aktivität von Genen über die Untersuchung der gebildeten mRNA-Transkripte. Diese Daten können ergänzt werden durch hochauflösende Mikroskopieverfahren wie RNA-FISH (Fluoreszenz-in-situ-Hybridisierung von RNA) bzw. sogenannte ,in situ“ PCR-Verfahren (Stichwort „spatial transcriptomics“) in Gewebeschnitten, d. h. Proben, in denen die Zellen noch räumlich angeordnet sind und nicht vereinzelt. Beide Verfahren geben zusätzliche Aufschlüsse über die räumliche Verteilung der Genexpression zellspezifischer „Markierungs“-Gene, d. h. sie ermöglichen die räumliche Zuordnung von Zellen entsprechend bestimmter Signaturen und können dann mit Einzelzelldaten zusammengebracht werden.

41 „Omics“ ist ein Neologismus, der unterschiedliche Forschungsfelder der Lebenswissenschaften beschreibt, bei denen der Fokus der Studien auf dem gesamten zellulären Gehalt an den untersuchten Molekülen liegt (zu den Molekülgruppen siehe Text).

42 Zur Nutzung der Methode für die Untersuchung von Entwicklungsübergängen bei verschiedenen Organismen siehe Junker et al. (2019).

43 Vgl. Fußnote 40. 
auf das Individuum bezogene, Medizin rückt in den Bereich des Möglichen. ${ }^{44}$ Ebenfalls durch die Einzelzellanalytik verändert wird die Erforschung von Organoiden, also von aus Stammzellen in vitro entwickelten Zellverbänden, die in Form, Zelltypzusammensetzung und Funktion bestimmte Eigenschaften und Funktionsweisen von Organen nachbilden (siehe Bartfeld et al., 2020; Stroulios et al., 2021; Taupitz, Kap. 15). Auch für die Erforschung des Immunsystems, etwa im Zusammenhang mit neuartigen CAR-TZell-Therapien ${ }^{45}$ gegen Krebs (siehe Fehse, Kap. 6), können Einzelzelldaten genutzt werden (Castellanos-Rueda et al., 2021).

Die Einzelzellanalytik lässt sich aber nicht nur bei Menschen und Tieren, sondern auch bei Mikroorganismen und Pflanzen anwenden. So werden bei Bakterien etwa Pathogenitäts- oder metabolische Unterschiede einzelner Zellen in einer Bakterienkolonie untersucht oder die Zusammensetzung von Mikroorganismen in gemischten Kulturen oder Biofilmen (Franklin et al., 2015; Chen et al., 2017). Bei Pflanzen ist die Vereinzelung von Zellen wegen der festen Zellwände von Pflanzenzellen schwieriger (Müller-Röber, 2019). Untersucht werden hier z. B. die Reaktion von Zellen auf einen Angriff von Pathogenen und Mechanismen der Resistenz gegen Krankheitserreger. Außerdem werden Einflüsse von Umweltbedingungen auf zelluläre Prozesse analysiert. Neu gewonnene Erkenntnisse könnten dabei zur gezielteren Züchtung und Verbesserung von Eigenschaften von Nutzpflanzen führen (für weiterführende Literatur siehe Müller-Röber, 2019).

Einzelzellanalysen benötigen umfassende Spezialkenntnisse und stellen hohe Anforderungen an die technische Ausstattung der Labore. Benötigt wird eine Standardisierung auf experimenteller Ebene und auf der Ebene der Dateninterpretation (Walter/ Gasparoni, 2019: 13). ${ }^{46}$ Daher wurden internationale Konsortien wie der Human Cell Atlas (HCA $)^{47}$ und LifeTime ${ }^{48}$ gegründet sowie Datenbanken für verschiedene Organis-

44 Siehe hierzu Aschenbrenner et al. (2019). Einzelzellanalysen verändern grundlegend unser Verständnis von Krebs und neurodegenerativen Erkrankungen. Erste Anwendungen befinden sich am Übergang zu klinischen Studien. Als Beispiel für eine praktische Anwendung in der Krebsmedizin siehe etwa den Übersichtsartikel von Xu et al. (2021) über die Nutzung von Einzelzellanalysen in der Diagnostik zirkulierender Tumorzellen sowie Binder et al. (2021) für die Erforschung von Melanomen in experimentellen und klinischen Settings.

45 CAR steht für Chimeric Antigen Receptor. Es handelt sich bei der CAR-T-Zellmethode um eine Krebsimmuntherapie, bei der patienteneigene T-Zellen (bestimmte Immunzellen) gentechnisch so verändert werden, dass sie synthetische antigenspezifische Rezeptoren enthalten, mit denen sie Krebszellen spezifisch erkennen und danach abtöten können. Für mehr Informationen siehe Siegmund-Schultze (2019) sowie Fehse (Kap. 6).

46 Zur Verbindung und Analyse verschiedener Arten von Einzelzelldaten siehe Stuart/Satija (2019).

47 Siehe unter: https://www.humancellatlas.org/ [22.03.2021].

48 Siehe unter: https://lifetime-initiative.eu [22.03.2021]. Siehe auch Junker et al. (2019). 
men angelegt, von denen zellspezifische Einzelzelldaten abgerufen werden können. ${ }^{49}$ In Deutschland wurde 2018 das vom BMBF geförderte Netzwerk Single Cell Omics Germany $(\mathrm{SCOG})^{50}$ gegründet, um die zahlreichen Forscher*innen miteinander zu vernetzen, die in Deutschland bereits an vielen spezialisierten Zentren mit Einzelzellanalysen arbeiten. Diese haben neben der experimentellen Infrastruktur in der Regel auch Methoden zur Datenerfassung, Datenspeicherung und Dateninterpretation erarbeitet. 2018 hat die Deutsche Forschungsgemeinschaft (DFG) vier neue DNA-Sequenzierzentren mit neuester Infrastruktur ausgestattet, ${ }^{51}$ die im Hochdurchsatz Daten auch für Einzelzellanalysen erzeugen können. Die darauffolgende bioinformatische Datenanalyse und -interpretation ist für Biologie und Medizin von zentraler Bedeutung. Es werden komplexere bioinformatisch-methodische Verfahren der Datenerfassung, der Qualitätskontrolle und der Datennutzung benötigt (siehe hierzu auch Aliee et al., 2019). In der Einzelzellanalytik werden multidimensionale Datensätze erzeugt, die einer einzelnen Referenz(-Person) zuzuordnen sind und gleichzeitig getrennt (Zelltyp) verglichen werden müssen. Diese Komplexität der Datenstruktur bedarf neuer Datenbank-Konzepte, die es zu entwickeln gilt. Zur effizienten Verarbeitung und Nutzung von großen Datenmengen werden auch zunehmend Methoden der künstlichen Intelligenz (KI) und des maschinellen Lernens (z. B. sog. Deep-Learning-Methoden) genutzt werden (Aliee et al., 2019; Scherer et al., 2021). Eine Herausforderung ist die Einbeziehung von klinischen und experimentellen Meta-Daten und die nachfolgende Übersetzung komplexer Einzelzelldaten in klinisch nutzbare Aussagen. Weil sich die Einzelzellanalytik so schnell entwickelt, müssen technische Voraussetzungen schnell etabliert werden und der Fortbildung im Umgang mit den Daten und den Technologien ein breiter Raum eingeräumt werden.

Neben den hohen Anforderungen an die Datenverarbeitung bleibt insbesondere die Vorbereitung und Verarbeitung von Einzelzellsuspensionen aus komplexen Geweben eine große Herausforderung. Die Gewinnbarkeit von RNA, DNA, Lipiden oder Proteinen in ausreichender Menge und Qualität ist sehr verschieden und die Verfahren dazu sind unterschiedlich sensitiv. Die auf RNA und DNA aufbauenden NGS Verfahren sind dabei technisch deutlich fortgeschrittener. Die Isolierung von Einzelzellen ist wie oben erwähnt bei bestimmten Organismen (z. B. Pflanzen) aber auch bei einigen menschlichen Geweben (wie dem Gehirn) besonders schwierig (siehe Walter/Gasparoni, 2019: 18). Teilweise umgeht man daher die Problematik der Zell-Vereinzelung, indem man nicht Zel-

49 Siehe unter: https://www.singlecell.de/index.php/resources/databases [22.03.2021].

50 Siehe unter: https://singlecell.de [22.03.2021].

51 Siehe unter: https://www.dfg.de/service/presse/Pressemitteilungen/2018/pressemitteilung_ nr_06/ [22.03.2021]. 
len sondern Zellkerne aus Geweben vereinzelt (Krishnaswami et al., 2016; Narayanan et al., 2020). Aus diesen lässt sich RNA und DNA gewinnen. In den meisten nachfolgenden Präparations-Verfahren werden dann Mikrofluidiksysteme eingesetzt, die eine Automatisierung und hohe Skalierung der experimentellen Arbeiten (Zellzahlen) erlauben (Fung et al., 2020).

Zusammenfassend ist festzustellen, dass moderne Einzelzellanalysen auf neu ausgerichteten technologischen Ansätzen beruhen, die sich mit einer rasenden Geschwindigkeit ausbreiten und bereits in vielen Laboren Anwendung finden. Einzelzelldaten sind extrem informationsreich und eröffnen komplexe neue biologische Einsichten im Bereich der quantitativen und qualitativen Biologie und Biomedizin. Die einzelzellbasierte Diagnostik wird in absehbarer Zukunft Einzug in die klinische Anwendung halten. Die Technologieentwicklung in der Einzelzellanalytik ist immer noch nicht abgeschlossen und einige Bereiche (Zell-Isolation, NGS Verfahren) erleben immer noch eine extrem schnelle technologische Transformation (Aldridge/Teichman, 2020). Datentechnisch stellt die Einzelzellanalytik erheblich höhere Ansprüche an den Umgang, die Vernetzung und die Interpretation von Daten und dies wird die interdisziplinäre Vernetzung in den Lebenswissenschaften befördern.

\subsubsection{Ethische Aspekte}

Aufgrund der potenziell breiten Einsatzmöglichkeiten der Einzelzellanalytik sollten ihr Einsatz und Nutzen ebenso erforscht und öffentlich diskutiert werden wie die Unschärfen und Grenzen der neuen Technologie. Die Einzelzellanalyse berührt einige ethische Fragen, die bereits aus den Debatten um andere Biotechnologien bekannt und von großer gesellschaftlicher Bedeutung sind, insbesondere der Umgang mit sensiblen medizinischen Daten (siehe auch Fangerau et al., 2019). Daher ist es wichtig, bestehende Regeln zum verantwortungsvollen Umgang mit Datensicherheit und Datensouveränität im Lichte der neuen Möglichkeiten zu prüfen und, falls nötig, zu überarbeiten. Eine kritische Auseinandersetzung mit den Daten sollte auch innerhalb der Forschung gestärkt werden, um Fehlinterpretationen und Fehleinschätzungen zu vermeiden.

Die Zusammenführung und gemeinsame Analyse von genetischen und Einzelzelldaten wird neue Interpretationsmöglichkeiten bieten und neue Dimensionen der individuellen Bestimmtheit im Sinne einer Vorhersagbarkeit eröffnen, also etwa zur Vorhersage von Krankheitsverläufen oder individuellen Krankheitsrisiken. Die Kenntnis von individualisierten Einzelzelldaten erweitert unsere Möglichkeiten, die individuelle Ausprägung der genetischen Basis zu verstehen. Der Zusammenhang zwischen Genotyp und Phänotyp könnte in einem Maße erkennbar werden, der Vorhersagen des Phä- 
notyps anhand zellulärer Merkmale erlaubt. Dann könnten etwa anhand einer Biopsie noch genauere Vorhersagen über zukünftige Erkrankungen oder Krankheitsverläufe als bisher möglich werden. Dies würde gegenüber herkömmlichen Gentests einen enormen Erkenntniszuwachs bedeuten.

Derartige Möglichkeiten müssen im Hinblick auf ihre ethischen und gesamtgesellschaftlichen Implikationen diskutiert werden. Besonders wichtig ist es, die Datensouveränität von möglichen Proband*innen sowie Patient*innen zu bewahren. Dafür gilt es insbesondere, Befunde verständlich zu kommunizieren, sodass sie von den Betroffenen verstanden und in ihrer Bedeutung eingeschätzt werden können. Welcher Umfang neuer Erkenntnisse bezüglich Genfunktionen und deren zellulärer Ausprägung sich hieraus ergeben wird, ist jedoch noch unklar.

\subsection{Literaturverzeichnis}

Albrecht, S. et al. (2017): „Green“ genetic engineering and genome editing. Towards a reorientation of science communication. In: TATuP - Zeitschrift für Technikfolgenabschätzung in Theorie und Praxis 26(3): 64-69. DOI: 10.14512/tatup.26.3.64.

Aldridge, S./Teichmann, S. A. (2020): Single cell transcriptomics comes of age. In: Nat Commun. 11(1): 4307. DOI: $10.1038 / \mathrm{s} 41467-020-18158-5$.

Aliee, H. et al. (2019): Analyse von Einzelzellgenomik - Daten mit Methoden des maschinellen Lernens. In: Walter, J./Schickl, H. (Hrsg.): Einzelzellanalyse in Forschung und Medizin. Eine Stellungnahme der interdisziplinären Arbeitsgruppe Gentechnologiebericht. Berlin-Brandenburgische Akademie der Wissenschaften, Berlin: 48-54.

Alphey, L. (2016): Can CRISPR-Cas9 gene drives curb malaria? In: Nat Biotechnol 34: 149-150. DOI: 10.1038/nbt.3473.

Andorno, R. et al. (2020): Geneva statement on heritable human genome editing: The need for course correction. In: Trends Biotechnol. 38(4): 351-354. DOI: 10.1016/j.tibtech.2019.12.022.

Aschenbrenner, A. et al. (2019): Einzelzell-Omics in der Biomedizin gestern, heute und morgen. In: Walter, J./Schickl, H. (Hrsg.): Einzelzellanalyse in Forschung und Medizin. Eine Stellungnahme der interdisziplinären Arbeitsgruppe Gentechnologiebericht. Berlin-Brandenburgische Akademie der Wissenschaften, Berlin: 38-45.

Baltimore, D. et al. (2015): A prudent path forward for genomic engineering and germline gene modification. In: Science 348(6230): 36-38.

Bartfeld, S. et al. (Hrsg.) (2020): Organoide. Ihre Bedeutung für Forschung, Medizin und Gesellschaft. Nomos, Baden-Baden.

Berliner Zeitung (2018): Genmanipulation in China: Forscher greifen mit Gen-Schere ins Erbgut ein - Zwillingsbabys sind gegen HIV immun. 26.11.2018. Unter: https://www.berliner-zeitung.de/zukunft-technologie/genmanipulation-in-china-forscher-greifen-mit-gen-schere-ins-erbgut-einzwillingsbabys-sind-gegen-hiv-immun-li.23553 [20.04.2021]. 
Binder, H. et al. (2021): Melanoma single-cell biology in experimental and clinical settings. In: Journal of Clinical Medicine. 10(3): 506. DOI: 10.3390/jcm10030506.

Broad Institute (2021): CRISPR timeline. Unter: https://www.broadinstitute.org/what-broad/areasfocus/project-spotlight/crispr-timeline [22.04.2021].

Castellanos-Rueda, R. et al. (2021): Leveraging single-cell sequencing for chimeric antigen receptor T cell therapies. In: Trends Biotechnol, Online-Publikation 05.04.2021. DOI: 10.1016/j.tibtech.2021.03.005.

Chen, Z. et. al. (2017): Tools for genomic and transcriptomic analysis of microbes at single-cell level. In: Front Microbiol. 8: 1831. DOI: 10.3389/fmicb.2017.01831.

Chhalliyil, P. et al. (2020): A real-time quantitative PCR method specific for detection and quantification of the first commercialized genome-edited plant. In: Foods. 9: 1245.

Cohen, J. (2019): The untold story of the „circle of trust" behind the world's first gene-edited babies. In: Science, Online-Publikation 01.08.2019. DOI: 10.1126/science. aay9400.

Council of Europe (1997/1999): The Convention for the Protection of Human Rights and Dignity of the Human Being with regard to the Application of Biology and Medicine („Oviedo Convention“). Unter: https://www.coe.int/en/web/conventions/full-list [27.08.21].

Deutscher Ethikrat (2019): Eingriffe in die menschliche Keimbahn. Stellungnahme. Deutscher Ethikrat, Berlin. Unter: https://www.ethikrat.org/fileadmin/Publikationen/Stellungnahmen/deutsch/ stellungnahme-eingriffe-in-die-menschliche-keimbahn.pdf [22.04.2021].

Dürnberger, C. (2019): Natur als Widerspruch. Die Mensch-Natur-Beziehung in der Kontroverse um die Grüne Gentechnik. TTN-Studien 8. Nomos, Baden-Baden.

Doudna, J. A./Charpentier, E. (2014): The new frontier of genome engineering with CRISPR-Cas9. In: Science 346(6213): 1077. DOI: 10.1126/science.1258096.

EGE = European Group on Ethics in Science and New Technologies (2021): EGE opinion on the ethics of genome editing. Publications Office of the European Union, Luxemburg. DOI: 10.2777/659034.

Fachstelle Gentechnik und Umwelt (2018): CRISPR/Cas (Technik). Unter: https://fachstelle-gentechnik-umwelt.de/wp-content/uploads/CRISPR_Technik.pdf [22.04.2021].

Fangerau, H. et al. (2019): Einzelzellanalysen und Überlegungen zur Ethik. In: Walter, J./Schickl, H. (Hrsg.): Einzelzellanalyse in Forschung und Medizin. Eine Stellungnahme der interdisziplinären Arbeitsgruppe Gentechnologiebericht. Berlin-Brandenburgische Akademie der Wissenschaften, Berlin: 60-64.

Fehse, B./Abramowiski-Mock, U. (2021): Anwendung des Genome Editing in der somatischen Gentherapie. Eine Einführung. Springer-Verlag: Berlin.

Franklin, M. J. et al (2015): New technologies for studying biofilms. In: Microbiol Spectr. 3(4). DOI: 10.1128/microbiolspec.MB-0016-2014.

Fung, C. W. et al. (2020): Microfluidic single-cell analysis - Toward integration and total on-chip analysis. In: Biomicrofluidics. 14(2): 021502. DOI: 10.1063/1.5131795.

Garneau, J. E. et al. (2010): The CRISPR/Cas bacterial immune system cleaves bacteriophage and plasmid DNA. In: Nature 468: 67-71. DOI: 10.1038/nature09523. 
Gasiunas, G. et al. (2012): Cas9-crRNA ribonucleoprotein complex mediates specific DNA cleavage for adaptive immunity in bacteria. In: Proc Natl Acad Sci 109(39): E2579-E2586. DOI: 10.1073/ pnas.1208507109.

GeN = Genethisches Netzwerk (2019): Präzise Technik? Kritik an Genome-Editing. Stellungnahme. Unter: https://gen-ethisches-netzwerk.de/gen/positionspapier_genome_editing [21.04.2021].

GenTG = Gentechnikgesetz (1990): Gentechnikgesetz in der Fassung der Bekanntmachung vom 16. Dezember 1993 (BGBl. I S. 2066), mit der Änderung durch Artikel 95 der Verordnung vom 19. Juni 2020 (BGBl. I S. 1328). In: Bundesgesetzblatt: 1080-1095. Unter: https://www.bgbl.de/xaver/bgbl/start. xav?startbk=Bundesanzeiger_BGBl\&jumpTo=bgbl190s1080.pdf\#_-bgbl__\%2F\%2F*\%5B\%40attr_ id\%3D\%27bgbl190s1080.pdf\%27\%5D__1619021607418 [22.04.2021].

Glass, W. G. et al. (2005): Chemokine receptor CCR5 promotes leukocyte trafficking to the brain and survival in West Nile virus infection. In: J Exp Med. 202(8): 1087-1098. DOI: 10.1084/jem.20042530.

Gyngell, C. et al. (2017): The ethics of germline gene editing. In: Journal of Applied Philosophy 34(4). DOI: $10.1111 /$ japp.12249.

Hardt, A. (2019): Technikfolgenabschätzung des CRISPR/Cas-Systems. Über die Anwendung in der menschlichen Keimbahn. 1. Auflage. De Gruyter, Berlin/Boston.

Hsu, P. D. et al. (2014): Development and applications of CRISPR-Cas9 for genome engineering. In: Cell 157(6): 1262-1278. DOI: 10.1016/j.cell.2014.05.010.

Ishino, Y. et al. (1987): Nucleotide sequence of the iap gene, responsible for alkaline phosphatase isozyme conversion in Escherichia coli, and identification of the gene product. In: J Bacteriol. 169(12): 5429-5433. DOI: 10.1128/jb.169.12.5429-5433.1987.

Interdisziplinäre Arbeitsgruppe Gentechnologiebericht (2019): Kernaussagen und Handlungsempfehlungen zur Einzelzellanalytik. In: Walter, J./Schickl, H. (Hrsg.): Einzelzellanalyse in Forschung und Medizin. Eine Stellungnahme der interdisziplinären Arbeitsgruppe Gentechnologiebericht. Berlin-Brandenburgische Akademie der Wissenschaften, Berlin: 77-82.

Jasanoff, S. (2005): Designs on nature. Science and democracy in Europe and the United States. Princeton University Press, Princeton.

Jasanoff, S./Hurlbut, B. (2018): A global observatory for gene editing. In: Nature 555: 435-437. DOI: 10.1038/d41586-018-03270-w.

Jinek, M. et al. (2012): A programmable dual-RNA-guided DNA endonuclease in adaptive bacterial immunity. In: Science 337(6096): 816-821. DOI: 10.1126/science.1225829.

Junker, P. et al. (2019): Einzelzellgenomik verändert die Entwicklungsbiologie. In: Walter, J./Schickl, H. (Hrsg.): Einzelzellanalyse in Forschung und Medizin. Eine Stellungnahme der interdisziplinären Arbeitsgruppe Gentechnologiebericht. Berlin-Brandenburgische Akademie der Wissenschaften, Berlin: 23-37.

Krishnaswami, S. R. et al. (2016): Using single nuclei for RNA-seq to capture the transcriptome of postmortem neurons. In: Nat Protoc. 11(3): 499-524. DOI: 10.1038/nprot.2016.015.

Kronberg, I. (2019): Genschere Crispr-Cas9 in den Schlagzeilen: Genetik. In: Biologie in unserer Zeit 49(3): 169-170. DOI: 10.1002/biuz.201970308. 
Lander, E. S. (2016): The heroes of CRISPR. In: Cell. 164(1-2): 18-28. DOI: 10.1016/j.cell.2015.12.041.

Lander, E. S. et al. (2019): Adopt a moratorium on heritable genome-editing. In: Nature 567(7747): 165168. DOI: 10.1038/d41586-019-00726-5.

Ledford, H. (2017): Five big mysteries about CRISPR's origins. In: Nature 541(7637): 280-282. DOI: 10.1038/541280a.

Ledford, H. (2019): Super-precise new CRISPR tool could tackle a plethora of genetic diseases. In: Nature 574: 464-465. DOI: 10.1038/d41586-019-03164-5.

Leopoldina $=$ Deutsche Akademie der Naturforscher Leopoldina e.V (2015): Chancen und Grenzen des Genome-Editing. Unter: https://www.leopoldina.org/uploads/tx_leopublication/2015_3Akad_ Stellungnahme_Genome_Editing.pdf [21.04.2021].

Leopoldina et al. (2019): Wege zu einer wissenschaftlich begründeten, differenzierten Regulierung genomeditierter Pflanzen in der EU. Stellungnahme = Towards a scientifically justified, differentiated regulation of genome edited plants in the EU. Halle (Saale)/Bonn/Mainz.

Lettow, S. (2011): Biophilosophien. Wissenschaft, Technologie und Geschlecht im philosophischen Diskurs der Gegenwart. Campus, Frankfurt am Main/New York.

Liang, P. et al. (2015): CRISPR/Cas9-mediated gene editing in human tripronuclear zygotes. In: Protein \& Cell 6: 363-372. DOI: 10.1007/s13238-015-0153-5.

Liu, R. et al. (1996): Homozygous defect in HIV-1 coreceptor accounts for resistance of some multiplyexposed individuals to HIV-1 infection. Cell. 86(3): 367-377.

Makarova, K. S. et al. (2006): A putative RNA-interference-based immune system in prokaryotes: computational analysis of the predicted enzymatic machinery, functional analogies with eukaryotic RNAi, and hypothetical mechanisms of action. In: Biology Direct 1: 7.

Mojica, F. J. et al. (2000): Biological significance of a family of regularly spaced repeats in the genomes of Archaea, Bacteria and mitochondria. In: Mol Microbiol. 36(1): 244-246. DOI: 10.1046/j.13652958.2000.01838.x.

Müller-Röber, B. (Hrsg.) (2015): Dritter Gentechnologiebericht. Analyse einer Hochtechnologie. Forschungsberichte der Interdisziplinären Arbeitsgruppen der Berlin-Brandenburgischen Akademie der Wissenschaften, 32. Nomos, Baden-Baden.

Müller-Röber, B. (2019): Einzelzell-Transkriptomanalyse in Pflanzen. In: Walter, J./Schickl, H. (Hrsg.): Einzelzellanalyse in Forschung und Medizin. Eine Stellungnahme der interdisziplinären Arbeitsgruppe Gentechnologiebericht. Berlin-Brandenburgische Akademie der Wissenschaften, Berlin: $55-59$.

Narayanan, A. et al. (2020): Nuclei isolation from fresh frozen brain tumors for single-nucleus RNAseq and ATAC-seq. In: J Vis Exp. (162). DOI: 10.3791/61542.

NASEM = National Academy of Medicine, National Academy of Sciences, and the Royal Society (2020): Heritable human genome-editing. The National Academies Press, Washington. DOI:10.17226/25665.

Nuffield Council on Bioethics (2018): Genome-editing and human reproduction. Social and ethical issues. Nuffield Council on Bioethics, London.

Nunez, J. K. et al. (2021): Genome-wide programmable transcriptional memory by CRISPR-based epigenome editing. In: Cell 184(9): 2503-2519.e17. DOI: 10.1016/j.cell.2021.03.025.

O’Keefe, M. et al. (2015): „Editing“ genes: A case study about how language matters in bioethics. In: Am J Bioeth. 15(12): 3-10. DOI: 10.1080/15265161.2015.1103804. 
Osterheider, A. et al. (2019): Problemfelder und Indikatoren zum Thema Einzelzellanalyse. In: Walter, J./Schickl, H. (Hrsg.): Einzelzellanalyse in Forschung und Medizin. Eine Stellungnahme der interdisziplinären Arbeitsgruppe Gentechnologiebericht. Berlin-Brandenburgische Akademie der Wissenschaften, Berlin: 66-76.

Ranisch, R. (2018): CRISPR-Eugenik? Kritische Anmerkungen zur historischen Bezugnahme in der gegenwärtigen Verhandlung der Genom-Editierung. In: Ranisch, R. et al. (Hg.): Genome Editing Quo vadis? Ethische Fragen zur CRISPR/Cas-Technik. Königshausen \& Neumann, Würzburg: 27-52.

Regalado, A. (2019): China's CRISPR babies: Read exclusive excerpts from the unseen original research. MIT Technology Review, Online-Publikation 03.12.2019. Unter: https://www.technologyreview.com/2019/12/03/131752/chinas-crispr-babies-read-exclusive-excerpts-he-jiankui-paper/ [17.08.2021].

Reich, J. et al. (Hrsg.) (2015): Genomchirurgie beim Menschen - zur verantwortlichen Bewertung einer neuen Technologie. Eine Analyse der Interdisziplinären Arbeitsgruppe Gentechnologiebericht. Berlin-Brandenburgische Akademie der Wissenschaften, Berlin.

Rosemann, A. et al. (2019): Heritable genome editing in a global context: National and international policy challenges Hastings Center Report 49(3): 30-42. DOI: 10.1002/hast.1006.

Scherer, M. et al. (2021): Machine learning for deciphering cell heterogeneity and gene regulation. In: Nature Computational Science 1: 183-191, Online-Publikation 15.03.2021. DOI: 10.1038/s43588021-00038-7.

Siegmund-Schultze, N. (2019): CAR-T-Zellen. Hoffnung und Hype. und Neue Strategie in der Onkologie. CAR-T-Zellen erreichen die klinische Praxis. In: Deutsches Ärzteblatt 116(49).

Stroulios, G et al. (2021): Culture methods to study apical-specific interactions using intestinal organoid models. In: J Vis Exp. 169. DOI: 10.3791/62330.

Stuart, T./Satija, R. (2019): Integrative single-cell analysis. In: Nat Rev Genet. 20(5): 257-272. DOI: 10.1038/s41576-019-0093-7.

TA-Swiss (2019): Genome Editing - Interdisziplinäre Technikfolgenabschätzung. In TA-SWISS Publikationsreihe TA 70/2019. Vdf, Zürich.

Tebas, P. et al. (2014): Gene editing of CCR5 in autologous CD4 T cells of persons infected with HIV. In: N Engl J Med 370(10): 901-910.

Walter, J./Gasparoni, N. (2019): Einleitung. In: Walter, J./Schickl, H. (Hrsg.) (2019): Einzelzellanalyse in Forschung und Medizin. Eine Stellungnahme der interdisziplinären Arbeitsgruppe Gentechnologiebericht. Berlin-Brandenburgische Akademie der Wissenschaften, Berlin: 10-20.

Walter, J./Schickl, H. (Hrsg.) (2019): Einzelzellanalyse in Forschung und Medizin. Eine Stellungnahme der interdisziplinären Arbeitsgruppe Gentechnologiebericht. Berlin-Brandenburgische Akademie der Wissenschaften, Berlin.

Walter, J. et al. (2019): Kernaussagen und Handlungsempfehlungen zur Einzelzellanalytik. In: Walter, J./Schickl, H. (Hrsg.): Einzelzellanalyse in Forschung und Medizin. Eine Stellungnahme der interdisziplinären Arbeitsgruppe Gentechnologiebericht. Berlin-Brandenburgische Akademie der Wissenschaften, Berlin: 77-83. 
WHO = World Health Organisation (2020): A DRAFT governance framework for human genome editing. Unter: https://www.who.int/ethics/topics/human-genome-editing/Governance-frameworkfor-HGE-Jan2020.pdf?ua=1 [22.04.2021].

$\mathrm{Xu}, \mathrm{M}$. et al. (2021): Design and clinical application of an integrated microfluidic device for circulating tumor cells isolation and single-cell analysis. In: Micromachines. 12(1): 49. DOI: 10.3390/ mi12010049.

Zeit (2008): Der letzte Tabubruch der Gentechnik? 26.11.2018. Unter: https://www.zeit.de/ wissen/2018-11/crispr-china-geburt-zwillinge-erbanlage-genveraenderung-hiv-resistenz [20.04.2021]. 